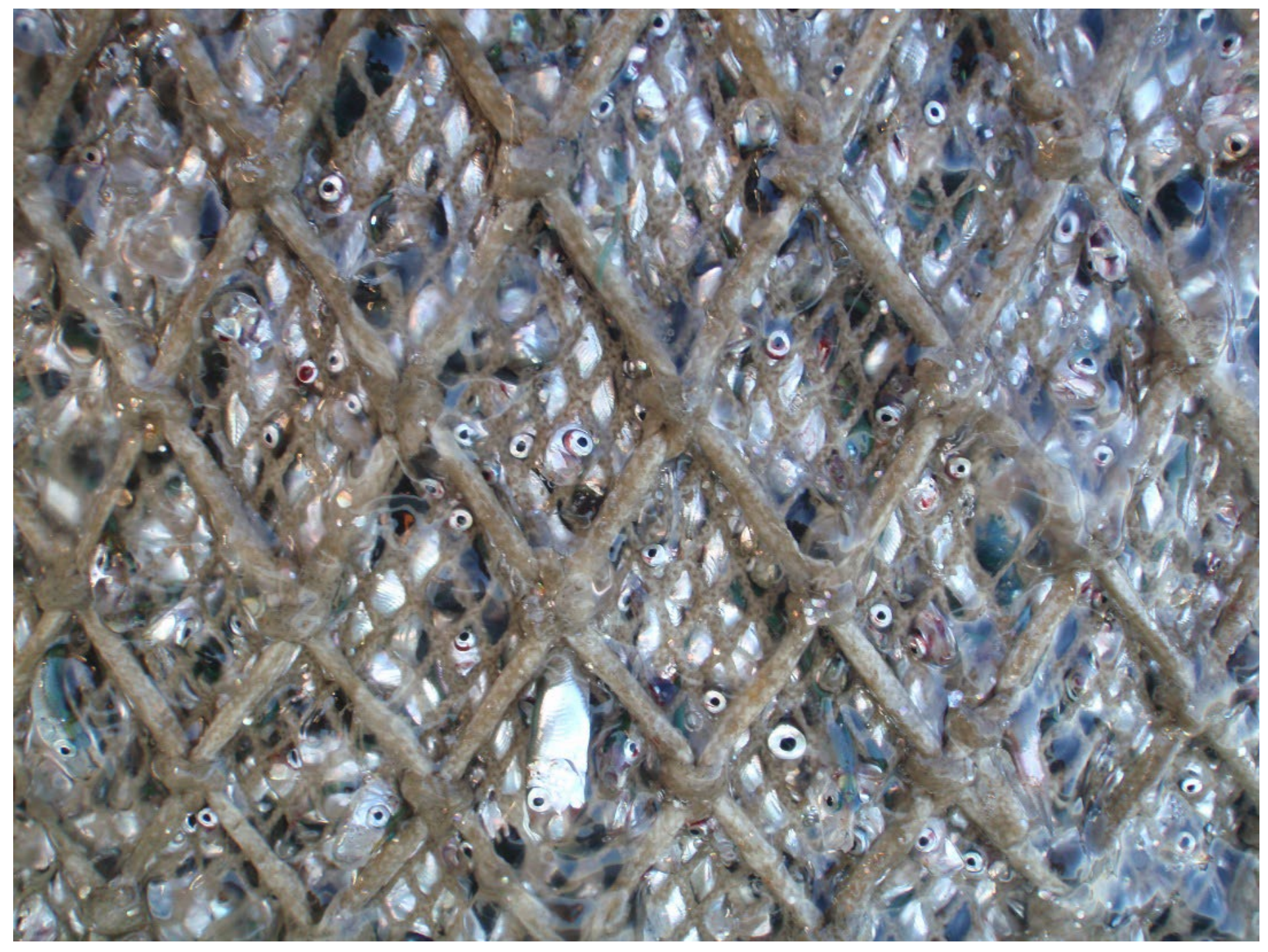

\title{
Ankerkuilbemonstering in de Westerschelde Resultaten 2018 en meerjarenoverzichten
}




\section{Ankerkuilbemonstering in de Westerschelde}

Resultaten 2018 en meerjarenoverzichten

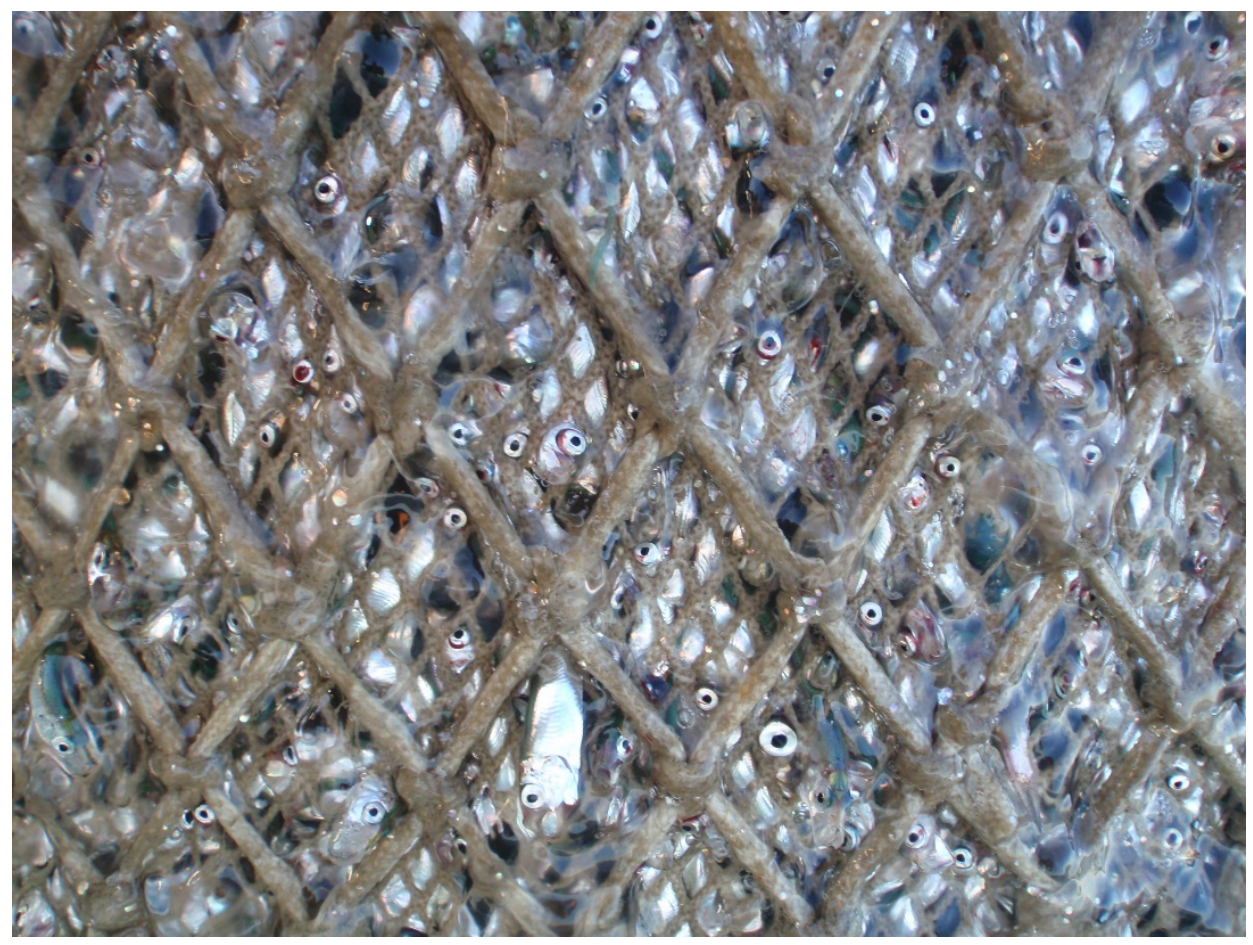

Auteurs:

I.J. de Boois, A.S. Couperus

Publicatiedatum: 13 december 2018

Wageningen Marine Research IJmuiden, december 2018

VERTROUWELIJK Nee

Wageningen Marine Research rapport C085/18 
I.J. de Boois en A.S. Couperus, 2018 , Ankerkuilbemonstering in de Westerschelde Resultaten 2018 en meerjarenoverzichten Wageningen Marine Research Wageningen UR (University \& Research centre), Wageningen Marine Research rapport C085/18. 335 blz.

Keywords: Ankerkuilvisserij, Westerschelde, Kaderrichtlijn water

Opdrachtgever: Rijkswaterstaat

Water, Verkeer en Leefomgeving

T.a.v. Mervyn Roos

Postbus 17

8200 AA Lelystad

RWS rapportnummer: BM 18.26

Dit rapport is gratis te downloaden van https://doi.org/10.18174/464614

Wageningen Marine Research verstrekt geen gedrukte exemplaren van rapporten.

Wageningen Marine Research Wageningen UR is ISO 9001:2015 gecertificeerd.

Foto omslag: B. Couperus

\section{(C) 2018 Wageningen Marine Research}

Wageningen Marine Research, onderdeel van Stichting Wageningen Research KvK nr. 09098104,

IMARES BTW nr. NL 8113.83.696.B16. Code BIC/SWIFT address: RABONL2U IBAN code: NL 73 RABO 0373599285
De Directie van Wageningen Marine Research is niet aansprakelijk voor gevolgschade, noch voor schade welke voortvloeit uit toepassingen van de resultaten van werkzaamheden of andere gegevens verkregen van Wageningen Marine Research opdrachtgever vrijwaart Wageningen Marine Research van aanspraken van derden in verband met deze toepassing.

Dit rapport is vervaardigd op verzoek van de opdrachtgever hierboven aangegeven en is zijn eigendom. Niets uit dit rapport mag weergegeven en/of gepubliceerd worden, gefotokopieerd of op enige andere manier gebruikt worden zonder schriftelijke toestemming van de opdrachtgever. 


\section{Inhoud}

$\begin{array}{lr}\text { Samenvatting } & 4\end{array}$

$1 \quad$ Inleiding $\quad 5$

2 Reisverslagen $2018 \quad 6$

2.1 Voorjaar 26

$\begin{array}{ll}2.2 \text { Najaar } & 7\end{array}$

$\begin{array}{lll}2.3 & \text { Ruimte voor verbetering } & 8\end{array}$

$\begin{array}{lll}\text { 2.3.1 Algemeen } & 8\end{array}$

$\begin{array}{lll}\text { 2.3.2 Analyse van gegevens } & 8\end{array}$

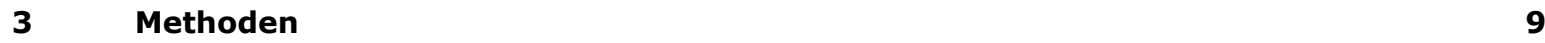

3.1 Gegevens op de bemonsteringslocaties 9

$\begin{array}{lll}3.1 .1 & \text { Locaties } & 10\end{array}$

3.1.2 Hoogte waterkolom 10

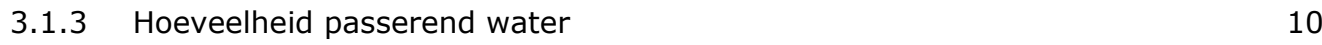

3.2 Vangstverwerking 11

3.3 Controle en opwerking van gegevens 12

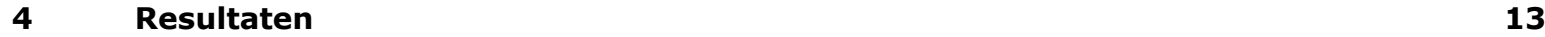

$\begin{array}{lll}4.1 & \text { Bemonstering } 2018 & 13\end{array}$

4.1.1 Bemonstering 13

4.1.2 Soortsamenstelling, aantal en biomassa 14

$\begin{array}{lll}4.1 .3 & \text { Lengte frequenties } & 18\end{array}$

$\begin{array}{lll}4.2 & \text { Resultaten 2008-2018 } & 20\end{array}$

$\begin{array}{lll}\text { 4.2.1 Gegevens per seizoen } & 20\end{array}$

4.2.2 Gegevens per locatie $\quad 22$

$5 \quad$ Discussie en conclusies $\quad 23$

$\begin{array}{lll}5.1 & \text { Mogelijke verdere analyses } & 23\end{array}$

$\begin{array}{llr}6 & \text { Kwaliteitsborging } & 24\end{array}$

$\begin{array}{lll}6.1 & \text { Determinatie van soorten } & 24\end{array}$

6.2 Wageningen Marine Research kwaliteitsmanagement $\quad 24$

$\begin{array}{lr}\text { Literatuur } & 25\end{array}$

$\begin{array}{lr}\text { Verantwoording } & 26\end{array}$

\begin{tabular}{|rr} 
Bijlage 1 Gegevens per locatie 2008-2018 & 27
\end{tabular}

$\begin{array}{ll}\text { Borssele } & 28\end{array}$

$\begin{array}{lr}\text { Brouwersplaat } & 29\end{array}$

$\begin{array}{ll}\text { Paulinapolder } & 30\end{array}$

$\begin{array}{ll}\text { Valkenisse } & 31\end{array}$

$\begin{array}{ll}\text { Bijlage } 2 \text { Overige soorten } 2018 & 32\end{array}$ 


\section{Samenvatting}

In 2018 is voor het elfde jaar de visbemonstering met de ankerkuil op de Westerschelde uitgevoerd in het kader van de monitoring voor de Kaderrichtlijn Water, sinds 2011 in combinatie met een identieke bemonstering op de Zeeschelde in België met hetzelfde schip en vistuig. De monitoring van vooral het pelagische visbestand is van belang in het kader van het herstel en de instandhoudingsdoelen van Natura2000, de Kaderrichtlijn Water en de monitoring van de effecten van verdieping van de vaargeul in de Schelde. De toegepaste methode is een passieve vistechniek die gebruik maakt van de getijstromen en die gericht is op pelagische soorten. Dagelijks wordt één vloedperiode en één ebperiode bemonsterd, die bij daglicht. Dit rapport presenteert de verzamelde gegevens van de Nederlandse bemonsteringen in mei en september 2018 en een overzicht over de totale bemonsteringsperiode.

Op vier locaties (Schaar van Valkenisse, Brouwersplaat, Borssele, Paulinapolder) zijn in 2018 in totaal 29 monsters genomen, 14 in het voorjaar en 15 in het najaar. Alleen bij een gunstige combinatie van wind en stroomrichting kan met beide vistuigen tegelijk worden gevist. In het voorjaar is tijdens zes trekken (12 monsters) simultaan met stuurboord en bakboord uitgevoerd. In het najaar gold dat voor slechts één trek ( 2 monsters). Door ongunstige combinatie van wind en stroming was het in 2018 een aantal maal nodig om op de kentering naar een zo dichtbij mogelijk gelegen alternatieve vislocatie uit te wijken.

In 2018 is een extreme vangst met aasgarnalen gedaan bij Borssele (voorjaar, met vloed). Mede hierdoor werd een extreme hoeveelheid slakdolf gevangen in diezelfde trek; de aasgarnalen zorgden ervoor dat de slakdolf niet zonder meer door de mazen van het net kon.

In september 2018 was het doodtij (weinig tijverschil) tijdens de bemonstering. Het effect daarvan op de vangsten is onduidelijk, maar mogelijk wel aanwezig.

Naast diverse vissoorten zijn voornamelijk veel ribkwallen aangetroffen: zeedruif (Pleurobrachia pileus) en Amerikaanse langlobribkwal (Mnemiopsis leidyi). Daarnaast is de poliepkwal Parasolletje (Eutonina indicans) aangetroffen. In het voorjaar was de zeedruif abundanter en in het najaar de Amerikaanse langlobribkwal. In het najaar werden ook exemplaren van poliepkwallen Eucheilota maculata (geen Nederlandse naam), Kruiskopkwalletje (Nemopsis bachei) en Kleine klokpoliep (Clythia hemisphaerica) aangetroffen.

De vangsten van schijfkwallen volgen het reguliere patroon van voorkomen: oorkwal (Aurelia aurita) en haarkwal (Cynaea sp.) in het voorjaar, kompaskwal (Chrysaora hysoscella)en zeepaddestoel (Rhizostoma octopus) in het najaar. 


\section{$1 \quad$ Inleiding}

De Westerschelde is een min of meer natuurlijk estuarium in het Nederlandse deltagebied waar een geleidelijke overgang van zoet Schelde rivierwater naar zout Noordzee zeewater plaatsvindt. De enige andere zoet-zoutovergang in het deltagebied is het (gegraven) kanaal van de Nieuwe Waterweg waar het water van Rijn en Maas door stroomt. De in volume belangrijkste uitwatering van Maas en Rijn zijn de sluizen bij het Haringvliet die nu nog voor een abrupte overgang van zoet naar zout water zorgen. Sinds 15 november 2018 is met de uitvoering van "het Kierbesluit" het een overgangsgebied van zoet naar zout water hersteld. Naast de Schelde is de Eems het enige andere overgebleven min of meer natuurlijke estuarium in Nederland.

Op de Schelde wordt monitoring van pelagische vis met een ankerkuil uitgevoerd in het kader van de Europese Kaderrichtlijn Water. In Nederland wordt dit op de Westerschelde sinds 2007 jaarlijks twee maal per jaar uitgevoerd met een onderbreking in 2010. Sinds 2011 wordt dit door België op identieke wijze, met hetzelfde schip en vistuig, uitgevoerd op de Zeeschelde en vormt een geheel met de Nederlandse bemonstering. De bemonstering in Nederland wordt in het voor- en najaar uitgevoerd, die in België in het voorjaar, de zomer en het najaar. In het voor- en najaar sluiten de Belgische en Nederlandse bemonsteringsweken op elkaar aan. Zowel in België als in Nederland worden vier locaties zowel bij eb als bij vloed bevist, zodat er per seizoen steeds een reeks van acht plaatsen in een aaneengesloten periode van twee weken wordt bemonsterd.

In dit rapport worden de data gepresenteerd van de Nederlandse bemonstering van de Westerschelde in 2018. 


\section{Reisverslagen 2018}

\section{$2.1 \quad$ Voorjaar}

Opstappers: Ingeborg de Boois, Margriet van Asch, Mervyn Roos (30 april); Ingeborg de Boois, Xander de Boer (1-3 mei)

Gebruikte samplenummers: 5000041-5000054

Schade aan vistuig: geen

\section{Maandag 30 april 2018}

Om 7 uur vertrokken vanuit Hansweert. De hele dag gevist bij de Schaar van Valkenisse, eerst op de ebstroom en daarna op de vloedstroom. In beide gevallen met twee tuigen kunnen vissen. Op de eb 1 uur met bakboord en 2 uur met stuurboord gevist, op de vloed 1 uur met stuurboord en 2 uur met bakboord.

In alle trekken spiering, haring, sprot, bot, tong, kleine en grote zeenaald, wat garnaal en steurgarnalen en in elke trek vislarven.

Tijdens de eb zat in zowel bak- als stuurboord rode poon. Op de vloedstroom zat in beide netten Kleine zandspiering.

Tijdens de eerste trek was een defecte stroommeter ingezet (kapotte vleugel) dus die gegevens zijn niet ingevoerd. De flowmeter kan worden weggegooid en er zal een nieuwe moeten worden aangeschaft. Met laagwater is een CTD downcast gedaan met de Valeport CTD. Deze gegevens zijn toegevoegd aan de database.

Terug in Hansweert om 16 uur.

\section{Dinsdag 1 mei 2018}

Om kwart voor 7 uitgevaren uit Hansweert. Om 7.50 uitgezet bij Middelgat. Het kostte moeite om het schip op zijn plek te houden (sterke ebstroom in combinatie met westenwind kracht 6-7 Bft), alleen met bakboord kunnen vissen en slechts één uur. Wel een diverse vangst, met o.a. goudharder, zeeforel, 4 finten. Tijdens de kentering de CTD laten zakken. Dit werkte goed, dus op zich is dat een goed moment om één keer per dag informatie te verzamelen over temperatuur en zoutgehalte van het water. Op de vloed beide netten uitgezet, bakboord een uur en stuurboord iets meer dan 2 uur. Weinig stroming en kleine vangsten, haring, spiering, zandspiering, sprot. Enkele ribkwallen maar nog steeds weinig in vergelijking met voorgaande jaren. Vangstvolumes varieerden tussen 5 en 27 liter. Met laagwater (op de kentering) is een CTD downcast gedaan met de Valeport CTD. Deze gegevens zijn toegevoegd aan de database.

Aankomst in Terneuzen 15.30.

\section{Woensdag 2 mei 2018}

Om 6 uur vertrokken uit Terneuzen. Om 7.05 uitgezet bij de Paulinapolder met twee tuigen. Een uur en twee uur en 10 minuten gevist op de ebstroom. Vangsten met o.a. zeedruif (minder dan eerdere jaren maar meer dan op 30 april en 1 mei), haring, zeebaars, rivierprik, spiering, sprot, kleine zandspiering, kleine zeenaald, grote zeenaald, twee ansjovissen, harder (meegenomen) en koornaarvissen (meergenomen). Eén gezaagde steurgarnaal, een gewone zwemkrab (meegenomen). Uitzetten op de vloed was complexer; we verlegden het schip een stuk vanwege de flink toegenomen wind (ZZW 6-7). Vissen was alleen mogelijk met bakboord en slechts eenmaal (een uur en 10 minuten). De vangst bevatte zeedruiven, haarkwallen, haring, zeebaars, sprot, kleine zeenaald, kleine zandspiering.

Met laagwater is een CTD downcast gedaan met de Valeport CTD. Deze gegevens zijn toegevoegd aan de database.

Om 16 uur terug in Terneuzen. 


\section{Donderdag 3 mei 2018}

Om 6 uur vertrokken uit Terneuzen. Om 7.20 uitgezet bij Borssele met twee tuigen. Een uur resp. twee uur en 5 minuten gevist op de ebstroom. Beide netten zaten vol met aasgarnalen en daarom ook vol met kleine vis, o.a. veel slakdolven. In het bakboordnet zat een zeekat en zaten drie Sepiola's. Sepiola's zijn vers niet met zekerheid tot op de soort te identificeren. Op de vloed met twee netten gevist gedurende een uur resp. 2 uur. De vangsten waren beduidend kleiner en dat kwam waarschijnlijk door de veel kleinere hoeveelheid water die door het net was gestroomd. Er zaten geen aasgarnalen in deze vangsten, wel zeedruiven. Verder bevatte de vangst haring, zeebaars, sprot, kleine zeenaald, kleine zandspiering.

Met laagwater is een CTD downcast gedaan met de Valeport CTD. Deze gegevens zijn toegevoegd aan de database.

Om 17.00 in Hansweert. Spullen afgeladen en naar huis gereden.

\subsection{Najaar}

Opstappers: Bram Couperus, Margot Maathuis (17-20 september), Mervyn Roos (17 september) Gebruikte samplenummers: 5000061-5000075

Schade aan vistuig: geen

In tegenstelling tot de planning tijdens deze reis geen zoutgehalte en temperatuur (CTD; conductivity, temperature at depth) bemonstering uitgevoerd omdat twee van de drie CTD meetinstrumenten in gebruik waren en de derde technische problemen vertoonde.

Algemeen beeld hele week: weinig stroming (doodtij), lage vangsten en weinig (grote) spiering. Opvallend is de afwezigheid van kleine zeenaald. Net als vorig jaar in september bestond de vangst vooral uit Amerikaanse ribkwallen.

\section{Maandag 17 september 2018}

Margot Maathuis met de auto opgepikt bij station halfweg-Zwanenburg. Aan boord gekomen in Hansweert om 9:15. Mervyn Roos (RWS) was al aan boord.

Voor het uitzetten was er enig oponthoud doordat er een kabel niet op de juiste manier was doorgevoerd op het visblok van de bakboordgiek. Om 10:25 uitgezet met beide netten bij de Schaar van Valkenisse; een uur gevist met bakboord en twee uur met stuurboord op de vloedstroom. Daarna een uur gevist met stuurboord en twee uur met bakboord op de ebstroom. Vangsten bestonden voor een groot deel uit Amerikaanse ribkwallen, slechts een kleine zeenaald, geen bijzonderheden. Terug in Hansweert om 22:00. Mervyn Roos afgestapt.

\section{Dinsdag 18 september 2018}

Om 6:15 uur uitgevaren uit Hansweert. Uitgezet rond 7:05 uur met beide netten. Een uur gevist met stuurboord en 75 minuten met bakboord op de vloedstroom. Tijdens eb alleen met stuurboord gevist: 110 minuten. Weinig stroming tijdens eb.

Aankomst Terneuzen 16:00.

\section{Woensdag 29 september 2018}

Om 6:00 uur uitgevaren uit Terneuzen richting Paulinapolder. Er staat een stevige zuidwesten wind (5 $\mathrm{Bft}$ ). Achtereenvolgens om 8:07 uur een een uur en om 9:40 25 minuten gevist op bakboord in de vloedstroom, gevolgd door twee trekken van een uur in de ebstroom. Om 14:20 gehaald voor de laatste trek, aankomst Terneuzen 17:00. Wederom weinig stroming en lage vangsten.

\section{Donderdag 20 september 2018}

Rond 6:45 uur uitgevaren uit Terneuzen. Er staat nog steeds een stevige wind uit het zuidwesten die in de loop van de dag toeneemt naar $7 \mathrm{Bft}$. Om 8:20 en 10:41 uitgezet bij Borssele op de vloedstroom met bakboord. Tweemaal een uur gevist. De ebstroom was niet sterk genoeg, waardoor werd uitgeweken naar Zuid-Everingen. Hier werd twee keer voor een uur uitgezet met stuurboord. Omstreeks 16 uur terug in Hansweert, materiaal van de boot in het busje geladen, weegschaal en meettafel teruggebracht naar WMR Yerseke en naar huis gereden. 


\section{$2.3 \quad$ Ruimte voor verbetering}

\subsubsection{Algemeen}

Sinds 2016 wordt de bemonstering in voor- en najaar door verschillende onderzoekers uitgevoerd. Om de interne consistentie van de bemonstering en determinatie te behouden is het aan te raden dat ze soms beiden een dag aan boord zijn. Het voorstel is om in principe in de even jaren in het najaar één dag gezamenlijk aan boord te zijn, en in de oneven jaren in het voorjaar. Consistentie is voor de kwaliteit van de bemonstering van belang als voor de interpretatie van de data. Het was in 2018 niet mogelijk om gezamenlijk aan boord te zijn, door andere verplichtingen.

Wanneer registratie van zoutgehalte en temperatuur op verschillende dieptes gewenst is zal één van de CTDs gekalibreerd moeten worden zodat ook tijdens de najaarsbemonstering een CTD beschikbaar is.

\subsubsection{Analyse van gegevens}

\subsubsection{Vaststellen patronen in tijdserie}

In 2017 zijn voor het eerst de gegevens van de volledige tijdserie gerapporteerd. Er is geen statistische analyse uitgevoerd om eventuele patronen te herkennen. Indien dit voor de opdrachtgever relevant is kan dit in een volgende rapportage worden opgenomen. Hiervoor zal dan voor aanvang van de eerstvolgende monitoring een overleg met de opdrachtgever plaats moeten vinden om gezamenlijk vast te stellen welke analyses gedaan zouden moeten worden, en voor welke soorten. Eén van de aandachtspunten is het getij. Tijdens de septembersurvey 2018 was het doodtij, hetgeen invloed heeft op de vangsten, mogelijk als gevolg van minder stroming of ander doorzicht ten gevolge daarvan.

\subsubsection{Gebruik gegevens stroommeters}

Op dit moment worden gegevens van de stroommeters wel verzameld en opgeslagen maar niet gebruikt. De standaard opwerkingseenheid voor de Kaderrichtlijn Water is aantal en/of biomassa per $80 \mathrm{~m}^{2}$ per uur. De getijden-omstandigheden waaronder de monitoring plaatsvindt kunnen echter van jaar op jaar flink verschillen (bijv. gemiddeld tijverschil hoog- en laagwater najaar 20183.2 m, 2019 $4.8 \mathrm{~m}$ ). Dit betekent dat de hoeveelheid water die de Westerschelde in- en uitstroomt behoorlijk kan verschillen en dat komt niet tot uiting in de huidige opwerking.

Indien dit voor de opdrachtgever relevant is kan dit in een volgende rapportage worden opgenomen. Hiervoor zal voor aanvang van de eerstvolgende monitoring een overleg met de opdrachtgever plaats moeten vinden om gezamenlijk vast te stellen of dit meerwaarde heeft. 


\section{Methoden}

\subsection{Gegevens op de bemonsteringslocaties}

De bemonstering is gedaan met een ankerkuil. Bij deze visserijmethode wordt een net dat op vier hoekpunten met een anker verbonden is in de stroom van een viswater geplaatst. Dit gebeurt vanaf een schip dat aan datzelfde anker afgemeerd ligt. Twee horizontale 8 meter lange balken zijn door een staalkabel met elkaar verbonden waaraan de verticale zijden van het net zijn verbonden. De afstand tussen boven- en onderbalk is flexibel in te stellen tot maximaal 14 meter. Op die manier kan de hele waterkolom afgevist worden mits de stations ondieper zijn dan 14 meter. De maaswijdte van de zak van het net is $18 \mathrm{~mm}$ volle maas (mondelinge mededeling J. Bout 4 mei 2017), maar kan door gebruik wat krimpen (meting 2012: $16 \mathrm{~mm}$ ). In de gehele periode is hetzelfde net gebruikt. Onder ideale omstandigheden kan er met twee netten tegelijk worden gevist; één aan bakboord en één aan stuurboord. Wanneer stroom en wind tegengesteld zijn, is het niet mogelijk om twee netten tegelijk uit te zetten en wordt met één net tegelijk gevist. Meer informatie is te vinden in Goudswaard \& de Boois (2007).

Over de gehele monitoringsperiode is de uitvoering onveranderd gebleven en worden dezelfde netten gebruikt. Het schip is tussentijds wel gewijzigd, in 2012 is de TH27 vervangen door de TH16, maar heeft dezelfde schipper en vistuigen gehouden. Aangezien het een passieve visserij betreft is het niet te verwachten dat deze scheepswijziging tot verschillen in de vangst heeft geleid.

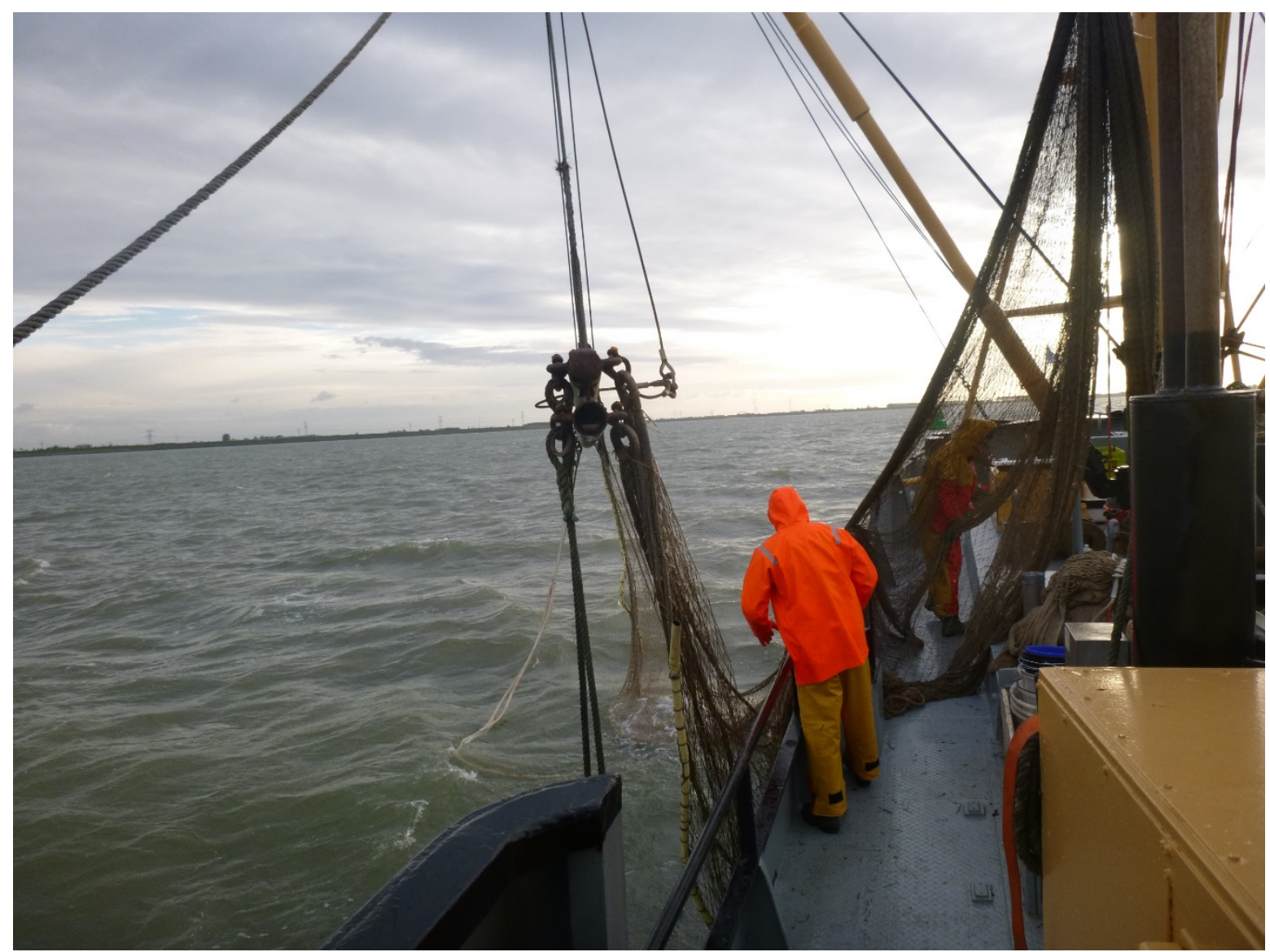

Het uitzetten van de ankerkuil (foto: I. de Boois) 


\subsubsection{Locaties}

Er wordt op vier locaties gevist. Dit betreft de posities: nabij de Schaar van Valkenisse/Plaat van Walsoorden, Brouwersplaat/Middelgat, het Gaatje bij Borssele en het vaarwater bij de Paulinapolder (Figuur 1). In 2018 is één van de locaties verlegd van Borssele naar Everdingen omdat de combinatie van wind en tijdrichting het niet toeliet om veilig en zinvol te bemonsteren op het station bij Borssele.

In Tabel 1 staan de coördinaten van het begin van de monstername in het rapportagejaar. Hoewel het anker een vaste positie heeft, giert het schip met de uitstaande vistuigen door de stroom waardoor de geografische positie iets verschuift. Dit blijft echter altijd binnen de decimalen van de minuten.

Het is de intentie om zowel bij eb als bij vloed minimaal één vangst te maken, meestal worden twee trekken uitgevoerd per getijperiode.

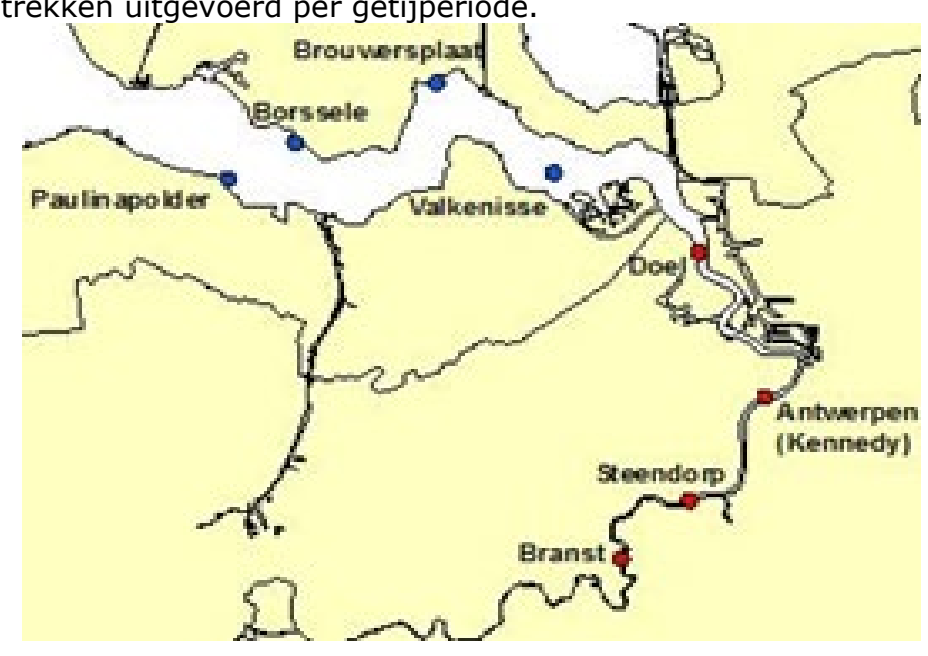

Figuur 1 Locaties van ankerkuil monsterpunten in het Schelde estuarium. De blauwe punten zijn de locaties in Nederland op de Westerschelde. De rode punten zijn die in België op de Zeeschelde.

\subsubsection{Hoogte waterkolom}

De hoogte van de beviste waterkolom is gegeven als het gemiddelde van de diepte bij de begin- en eindtijd. Dit is een ruwe benadering van de werkelijkheid omdat het schip op de getijdenstroom verschuift en in de geulen vrijwel altijd op een hellende zeebodem ligt. De hoogte van de kolom van het net is gelijk aan de diepte. De onderste balk van het net wordt op de grond gehouden. Wanneer de diepte meer dan 14 meter is, is de netopening onvoldoende en wordt de bovenste balk onder water gezet waardoor een deel van bovenste waterlaag niet wordt bevist. Dit gebeurt in de praktijk vrijwel nooit en ook in 2018 niet.

\subsubsection{Hoeveelheid passerend water}

De hoeveelheid passerend water kan worden berekend door (1) uit de gemiddelde nethoogte (waterdiepte) met de netbreedte (8 meter) het passage vlak en daarnaast (2) met een standaard stroommeter de horizontale waterpassage te bepalen. Hierdoor kan het totaal gepasseerde volume water worden berekend. De beperking van deze uitvoering is dat het gebruikte type stroommeter materiaal (bijv. plastic, zeewier) invangt en vasthoudt waardoor de registratie van het apparaat stopt. Dit gebeurt 1-2x per seizoen. De registratie is daarom wel uitgevoerd en opgenomen in de database, maar vooralsnog niet toegepast in de uitwerking. De resultaten worden daarom hier gerapporteerd in aantallen en biomassa's per uur vissen per $80 \mathrm{~m}^{2}$ passagevlak. Dat is ook de standaardwaarde die gebruikt wordt ten behoeve van rapportage voor de Kaderrichtlijn Water. 


\subsection{Vangstverwerking}

Alle vangsten zijn in emmers met maatverdeling (30 of 90 liter) opgevangen om het vangstvolume te bepalen. Indien noodzakelijk wordt direct daarna een deelmonster genomen om veel voorkomende kleine soorten zoals vislarven, kleine haringachtigen, kleine kwalachtigen en poliepkwallen, uit te sorteren. Ook van het deelmonster wordt het volume bepaald zodat de fractie ten opzichte van de totale vangst bekend is. De vangst, min het monster, is daarna in delen aan dek uitgestort en doorzocht op soorten die niet in het deelmonster voorkomen.

Van alle vis wordt een lengtefrequentieverdeling gemaakt. Deze zijn gebaseerd op lengtes die naar beneden worden afgerond tot de hele centimeter (bijvoorbeeld: 6.1 en 6.9 worden beiden als $6 \mathrm{~cm}$ geregistreerd, ook wel 'to the $\mathrm{cm}$ below') of millimeter. Oorspronkelijk werden alleen soorten met een maximum lengte van minder dan $21 \mathrm{~cm}$ op de millimeter nauwkeurig gemeten. Sinds 2017 worden in principe alle vissen 'to the $\mathrm{mm}$ below' gemeten omdat dat eenduidiger is. Alleen voor grote vangsten van vissoorten die langer kunnen worden dan $21 \mathrm{~cm}$, zoals wijting, wordt soms gekozen voor metingen 'to the $\mathrm{cm}$ below'.

Het gewicht van alle gemeten vis wordt per soort bepaald met een Marel 2000 series elektronische weegschaal met zeewaardige stabilisatie en kalibratie. De data zijn ingevoerd in het datastorage programma Billie Turf 8 en na kwaliteitscontrole opgeslagen in de database Frisbe van Wageningen Marine Research.

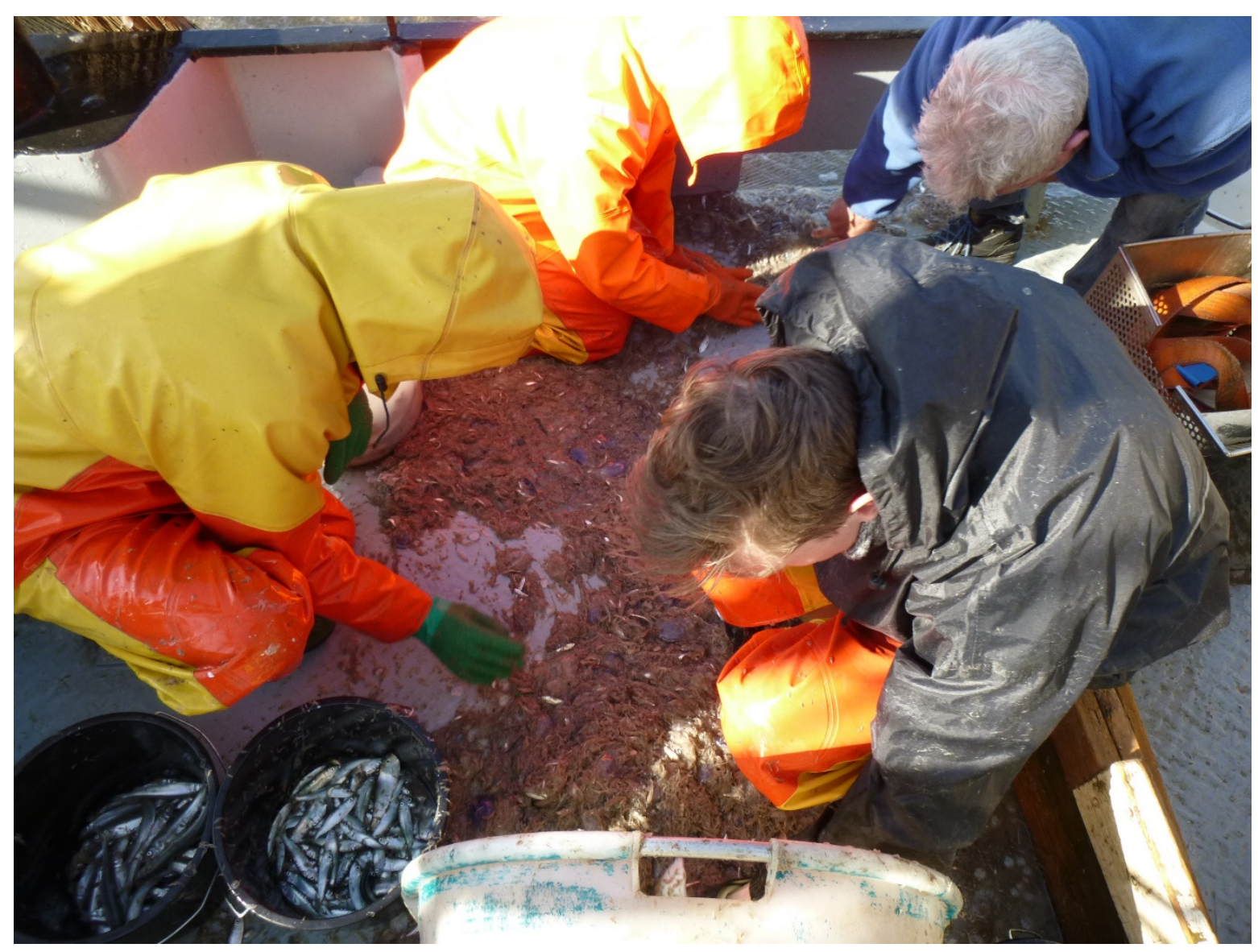

Vangsten worden uitgezocht nadat ze beetje bij beetje op het dek zijn gestort (foto: I. de Boois) 


\subsection{Controle en opwerking van gegevens}

De gegevens worden na gestandaardiseerde controle op de compleetheid, consistente naamgeving van bijv. stations en vistuig en extreme waardes (bijv. exceptionele lengtes), opgeslagen in de WMR database frisbe. Vandaaruit worden berekeningen uitgevoerd op de gegevens. Indien onvolkomenheden worden geconstateerd in de database worden deze aangepast, bij voorkeur in de basisfiles die dan gecorrigeerd opnieuw aan de database worden aangeboden. Indien bij hoge uitzondering wijzigingen direct in de database gedaan worden houdt de betreffende WMR databeheerder deze bij in een logboek.

De aantallen per trek zijn omgerekend naar aantallen per $80 \mathrm{~m}^{2}$ per visuur. Indien door omstandigheden de biomassa niet in het veld heeft kunnen plaatsvinden gebeurt omrekening naar biomassa door middel van centraal bij WMR beschikbare lengte-gewichtrelaties. Wijzigingen in deze relaties worden centraal bijgehouden door één van de databeheerders van WMR.

Ten behoeve van de lengteverdelingen zijn alle gevangen exemplaren in een seizoen opgeteld.

De aantallen of biomassa's per $80 \mathrm{~m}^{2}$ per visuur worden per trek opgeteld, en vervolgens eerst per seizoen, station en getijfase gemiddeld om te zorgen dat eventuele verschillen in bemonsteringsintensiteit niet van invloed zijn op de uitkomsten. Daarna zijn de gegevens gemiddeld per jaar per station. 


\section{Resultaten}

\subsection{Bemonstering 2018}

\subsubsection{Bemonstering}

Op de vier locaties zijn in 2018 in totaal 29 monsters genomen waarvan in het voorjaar de meerderheid en in het najaar slechts in twee gevallen simultaan met stuurboord en bakboord (Tabel 1, Tabel 2). Dit is alleen mogelijk bij een gunstige combinatie van wind en stroomrichting. In dat geval is de begintijd gelijk maar de duur van de monstername verschillend. In de overige gevallen is de monsterduur per getijperiode verdeeld over twee opeenvolgende monsters. Door ongunstige combinatie van wind en stroming was het in 2018 een aantal maal nodig om op de kentering naar een zo dichtbij mogelijk gelegen alternatieve vislocatie uit te wijken.

Tabel 1 Coördinaten in WGS 84 gegeven van de monsterpunten in 2018.

\begin{tabular}{|l|l|l|l|l|l|}
\hline & \multicolumn{4}{|c|}{ Voorjaar } & Najaar \\
\hline Locatie & Omschrijving & $\begin{array}{l}\text { Latitude } \\
(\mathbf{N B})\end{array}$ & $\begin{array}{l}\text { Longitude } \\
(\mathbf{O L})\end{array}$ & $\begin{array}{l}\text { Latitude } \\
(\mathbf{N B})\end{array}$ & $\begin{array}{l}\text { Longitude } \\
(\mathbf{O L})\end{array}$ \\
\hline Valkenisse & Plaat van Walsoorden & $51^{\circ} 22^{\prime} 77$ & $004^{\circ} 05^{\prime} 52$ & $51^{\circ} 22^{\prime} 80$ & $004^{\circ} 05^{\prime} 52$ \\
\hline Valkenisse & Plaat van Walsoorden & $51^{\circ} 23^{\prime} 04$ & $004^{\circ} 05^{\prime} 38$ & $51^{\circ} 23^{\prime} 42$ & $004^{\circ} 05^{\prime} 02$ \\
\hline Brouwersplaat & Middelgat bij ton MG13 & $51^{\circ} 26^{\prime} 73$ & $003^{\circ} 56^{\prime} 69$ & $51^{\circ} 27^{\prime} 45$ & $003^{\circ} 56^{\prime} 39$ \\
\hline Brouwersplaat & Middelgat bij ton MG13 & $51^{\circ} 26^{\prime} 74$ & $003^{\circ} 56^{\prime} 95$ & $51^{\circ} 25^{\prime} 52$ & $004^{\circ} 01^{\prime} 67$ \\
\hline Borssele & Gaatje van Borssele & $51^{\circ} 24^{\prime} 23$ & $003^{\circ} 46^{\prime} 44$ & $51^{\circ} 21^{\prime} 50$ & $003^{\circ} 49^{\prime} 98$ \\
\hline Borssele & Gaatje van Borssele & $51^{\circ} 24^{\prime} 14$ & $003^{\circ} 46^{\prime} 71$ & $51^{\circ} 21^{\prime} 82$ & $003^{\circ} 48^{\prime} 74$ \\
\hline Paulinapolder & $\begin{array}{l}\text { Vaarwater langs de } \\
\text { Paulinapolder }\end{array}$ & $51^{\circ} 21^{\prime} 94$ & $003^{\circ} 42^{\prime} 05$ & $51^{\circ} 21^{\prime} 18$ & $003^{\circ} 47^{\prime} 93$ \\
\hline Paulinapolder & $\begin{array}{l}\text { Vaarwater langs de } \\
\text { Paulinapolder }\end{array}$ & $51^{\circ} 22^{\prime} 77$ & $003^{\circ} 42^{\prime} 23$ & $51^{\circ} 21^{\prime} 18$ & $003^{\circ} 47^{\prime} 93$ \\
\hline
\end{tabular}

Tabel $2 \quad$ Kenmerken van monstermomenten in 2018.

\begin{tabular}{|l|l|l|r|r|r|l|}
\hline & Locatie & Datum & \multicolumn{1}{l}{$\begin{array}{l}\text { Tijd } \\
\text { zetten } \\
\text { (GMT) }\end{array}$} & \multicolumn{2}{l}{$\begin{array}{l}\text { Duur } \\
\text { (minuten) }\end{array}$} & \multicolumn{2}{l|}{$\begin{array}{l}\text { Diepte bij } \\
\text { zetten } \\
\text { (meter) }\end{array}$} & Getijde \\
\hline 1 & Valkenisse & $30-4-2018$ & 6.31 & 60 & 6.3 & eb \\
\hline 2 & Valkenisse & $30-4-2018$ & 6.31 & 120 & 6.3 & eb \\
\hline 3 & Valkenisse & $30-4-2018$ & 9.4 & 60 & 4.5 & vloed \\
\hline 4 & Valkenisse & $30-4-2018$ & 9.4 & 120 & 4.5 & vloed \\
\hline 5 & Brouwersplaat & $1-5-2018$ & 5.52 & 60 & 8.9 & eb \\
\hline 6 & Brouwersplaat & $1-5-2018$ & 9.55 & 60 & 6.6 & vloed \\
\hline 7 & Brouwersplaat & $1-5-2018$ & 9.55 & 130 & 6.6 & vloed \\
\hline 8 & Paulinapolder & $2-5-2018$ & 5.05 & 60 & 8.5 & eb \\
\hline 9 & Paulinapolder & $2-5-2018$ & 5.05 & 130 & 8.5 & eb \\
\hline 10 & Paulinapolder & $2-5-2018$ & 11.2 & 70 & 11.4 & vloed \\
\hline 11 & Borssele & $3-5-2018$ & 5.2 & 60 & 10.9 & eb \\
\hline 12 & Borssele & $3-5-2018$ & 5.2 & 125 & 10.9 & eb \\
\hline 13 & Borssele & $3-5-2018$ & 10.55 & 60 & 7.6 & vloed \\
\hline 14 & Borssele & $3-5-2018$ & 10.55 & 120 & 7.6 & vloed \\
\hline 15 & Valkenisse & $17-9-2018$ & 8.25 & 60 & 8.8 & eb \\
\hline 16 & Valkenisse & $17-9-2018$ & 10.25 & 120 & 8.8 & eb \\
\hline 17 & Valkenisse & $17-9-2018$ & 14.5 & 120 & 7.1 & vloed \\
\hline 18 & Valkenisse & $17-9-2018$ & 5.05 & 60 & 9.5 & vloed \\
\hline 19 & Brouwersplaat & $18-9-2018$ & & 120 & 7.1 & vloed \\
\hline
\end{tabular}




\begin{tabular}{|l|l|l|r|r|r|l|}
\hline 20 & Brouwersplaat & $18-9-2018$ & 5.05 & 75 & 9.5 & vloed \\
\hline 21 & Brouwersplaat & $18-9-2018$ & 9.15 & 110 & 8.2 & eb \\
\hline 22 & Paulinapolder & $19-9-2018$ & 6.07 & 60 & 9.1 & vloed \\
\hline 23 & Paulinapolder & $19-9-2018$ & 7.2 & 25 & 10 & vloed \\
\hline 24 & Paulinapolder & $19-9-2018$ & 10.05 & 60 & 11 & eb \\
\hline 25 & Paulinapolder & $19-9-2018$ & 11.3 & 60 & 10.5 & eb \\
\hline 26 & Borssele & $20-9-2018$ & 6.2 & 60 & 11.7 & vloed \\
\hline 27 & Borssele & $20-9-2018$ & 7.41 & 60 & 10.2 & vloed \\
\hline 28 & Borssele & $20-9-2018$ & 11.45 & 60 & 10.3 & eb \\
\hline 29 & Borssele & $20-9-2018$ & 12.55 & 60 & 8.6 & eb \\
\hline
\end{tabular}

\subsubsection{Soortsamenstelling, aantal en biomassa}

\subsubsection{Soortsamenstelling en identificatie}

\section{Vissen}

In 2018 zijn er in totaal 32 soorten vis tot op de soort geïdentificeerd, en drie combinaties van soorten (soorten niet te onderscheiden in het veld omdat de exemplaren bijv. te klein waren) aangetroffen. Daarnaast zijn 'vislarven' als groep meegenomen; deze zijn ook niet op genusniveau verder op naam te brengen. Het aantal soorten en combinaties van soorten is vergelijkbaar met voorgaande jaren. In het voorjaar van 2018 zijn 32 soorten/soortgroepen vis aangetroffen, in het najaar 17. Het aantal soorten per locatie en seizoen verschilt flink; het laagste aantal vissoorten in een monster werd aangetroffen bij Paulinapolder in het najaar met eb resp. in het voorjaar met vloed (7 soorten/soortgroepen) en het hoogste in het voorjaar bij Brouwersplaat met eb (23).

Er is in 2018 geen onderscheid gemaakt tussen de grondelsoorten. Het besluit om niet op soort te determineren is genomen omdat het te moeilijk en tijdrovend was om dit aan boord te doen en omdat er geen vriesfaciliteit was om monsters te bewaren voor latere determinatie in het lab.

In het voorjaar zijn monsters van de vislarven meegenomen om een indicatie te krijgen van de samenstelling. De in 2018 niet op soort gebrachte harders waren te klein om goed te determineren (1,5 resp. $3 \mathrm{~cm})$. In 2018 is voor het eerst sinds 2015 goudharder aangetroffen, tijdens de voorjaarsbemonstering.

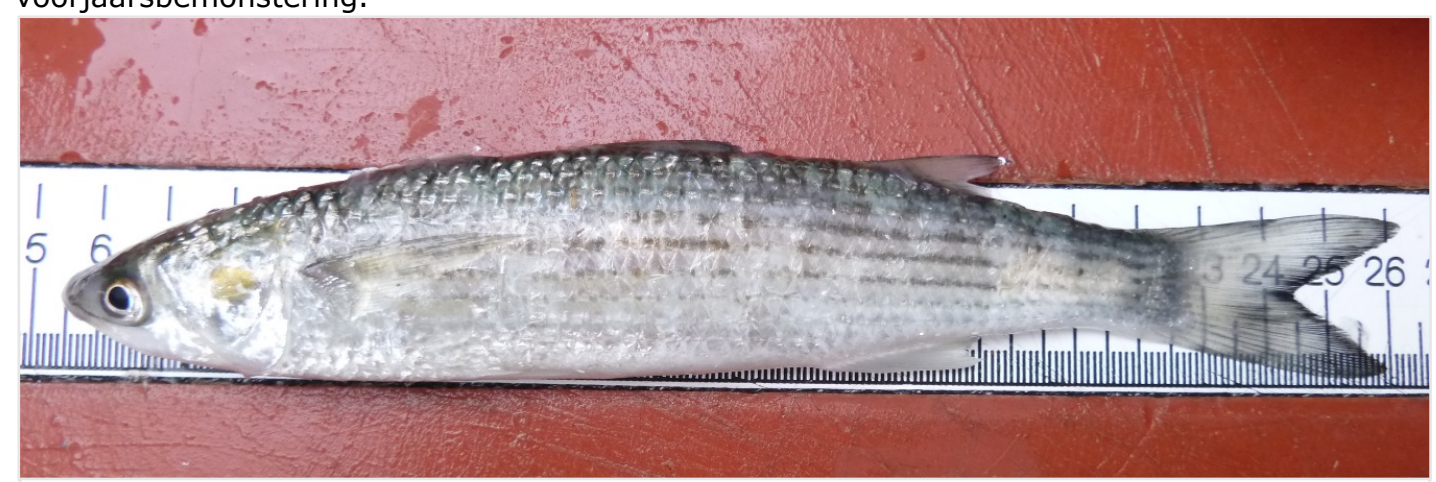

Goudharder (foto: I. de Boois)

\section{Overige soorten}

Naast diverse vissoorten zijn voornamelijk veel ribkwallen aangetroffen: zeedruif (Pleurobrachia pileus) en Amerikaanse langlobribkwal (Mnemiopsis leidyi). Daarnast is de poliepkwal Parasolletje (Eutonina indicans) aangetroffen. In het voorjaar was de zeedruif abundanter en in het najaar de Amerikaanse langlob ribkwal. In het najaar werden ook exemplaren van poliepkwallen Eucheilota maculata (geen Nederlandse naam), Kruiskopkwalletje (Nemopsis bachei) en Kleine klokpoliep (Clythia hemisphaerica) aangetroffen.

De vangsten van schijfkwallen volgen het reguliere patroon van voorkomen: oorkwal (Aurelia aurita) en haarkwal (Cynaea sp.) in het voorjaar, kompaskwal (Chrysaora hysoscella)en zeepaddestoel (Rhizostoma octopus) in het najaar. 


\subsubsection{Aantallen}

De gevangen aantallen zijn per soort per trek opgeteld en omgerekend naar aantallen per uur per $80 \mathrm{~m}^{2}$, per seizoen, locatie en per getijfase (Tabel 2). Opvallend was een enorme hoeveelheid aasgarnalen en slakdolven bij Borssele in het voorjaar met eb. Ansjovis is tijdens de voorjaarsbemonstering vrijwel niet gevangen en wel in het najaar. In het najaar werden vrijwel geen kleine zeenaalden gevangen.

\subsubsection{Biomassa}

De biomassa per soort (Tabel 4) is per trek bepaald door het doorgemeten monster te wegen. De biomassa's zijn op dezelfde manier opgewerkt als de aantallen. 


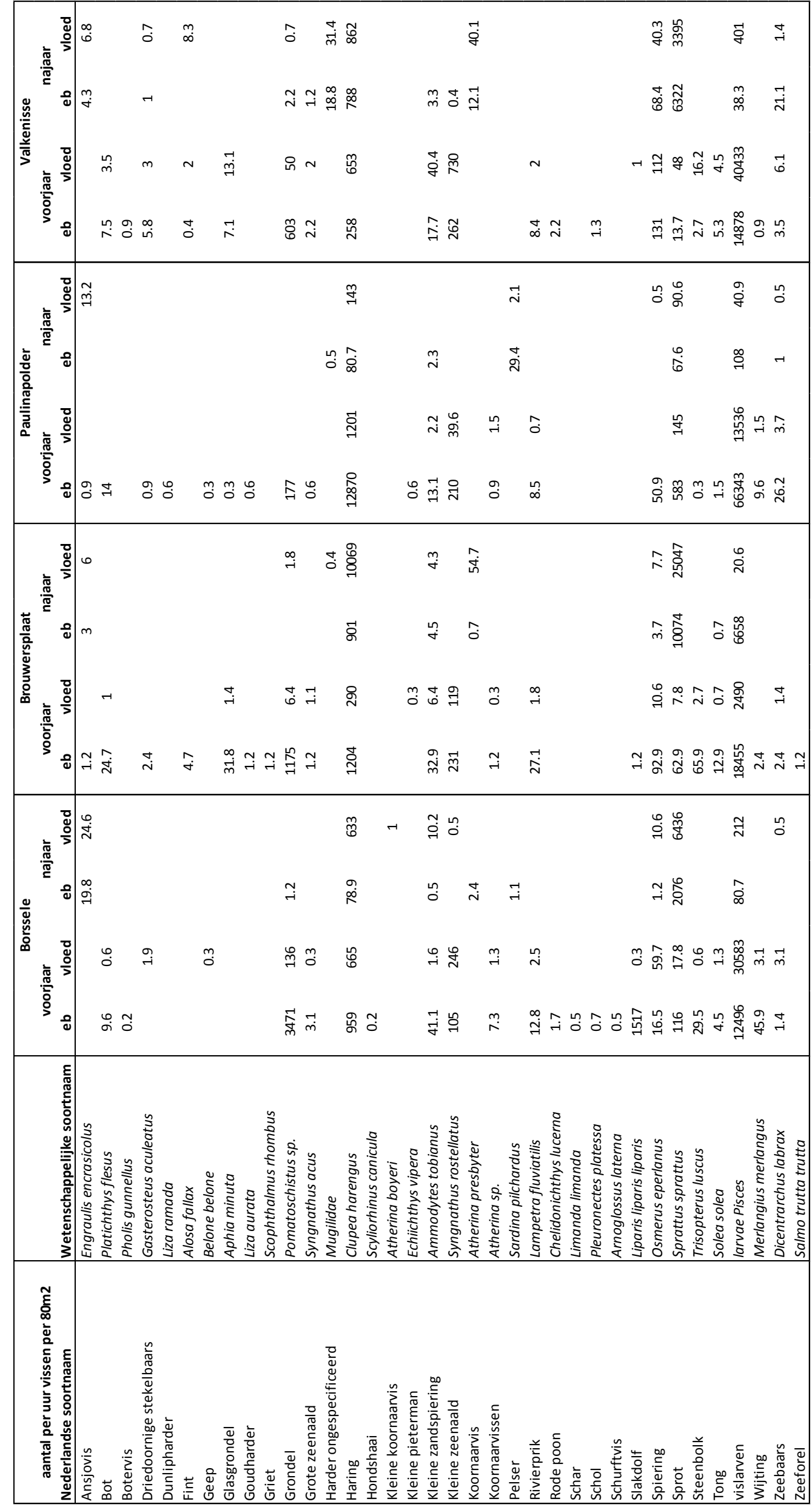


Tabel 4 Biomassa (gram per uur vissen per $80 \mathrm{~m}^{2}$ ), per locatie, seizoen en getijdenfase in 2018. (0.0: biomassa kleiner dan $0.05 \mathrm{~g}$, soort wel aangetroffen)

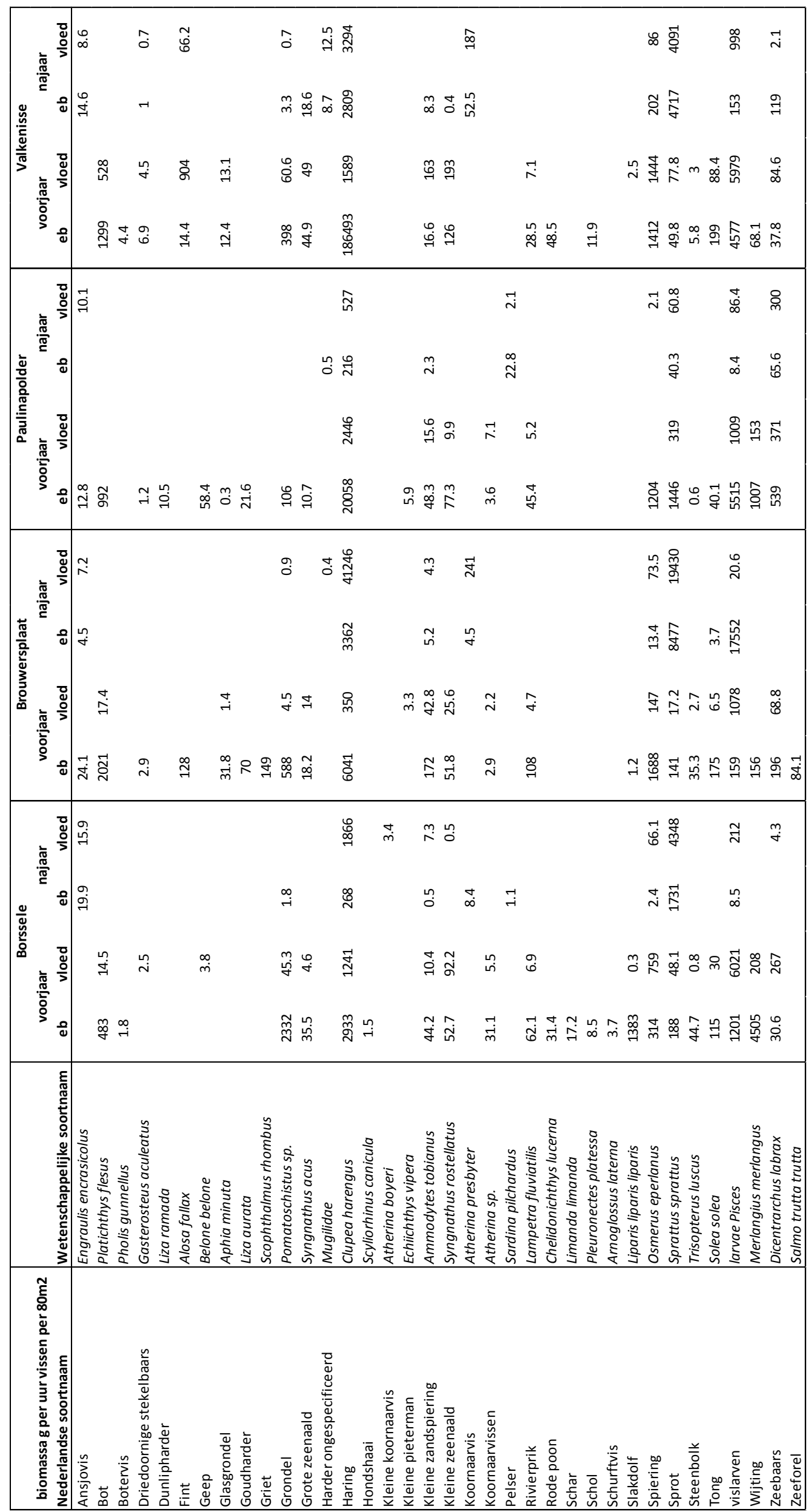




\subsubsection{Lengte frequenties}

\subsubsection{Pelagische vis}

Voor vier frequent gevangen pelagische vissoorten (haring, sprot, ansjovis, spiering) is de lengteverdeling weergegeven (Figuur 2).

In het voorjaar 2018 is in tegenstelling tot 2017 een enkele ansjovis gevangen (in 2017: geen). In het najaar werd evenals in eerdere jaren relatief veel kleine ansjovis aangetroffen.
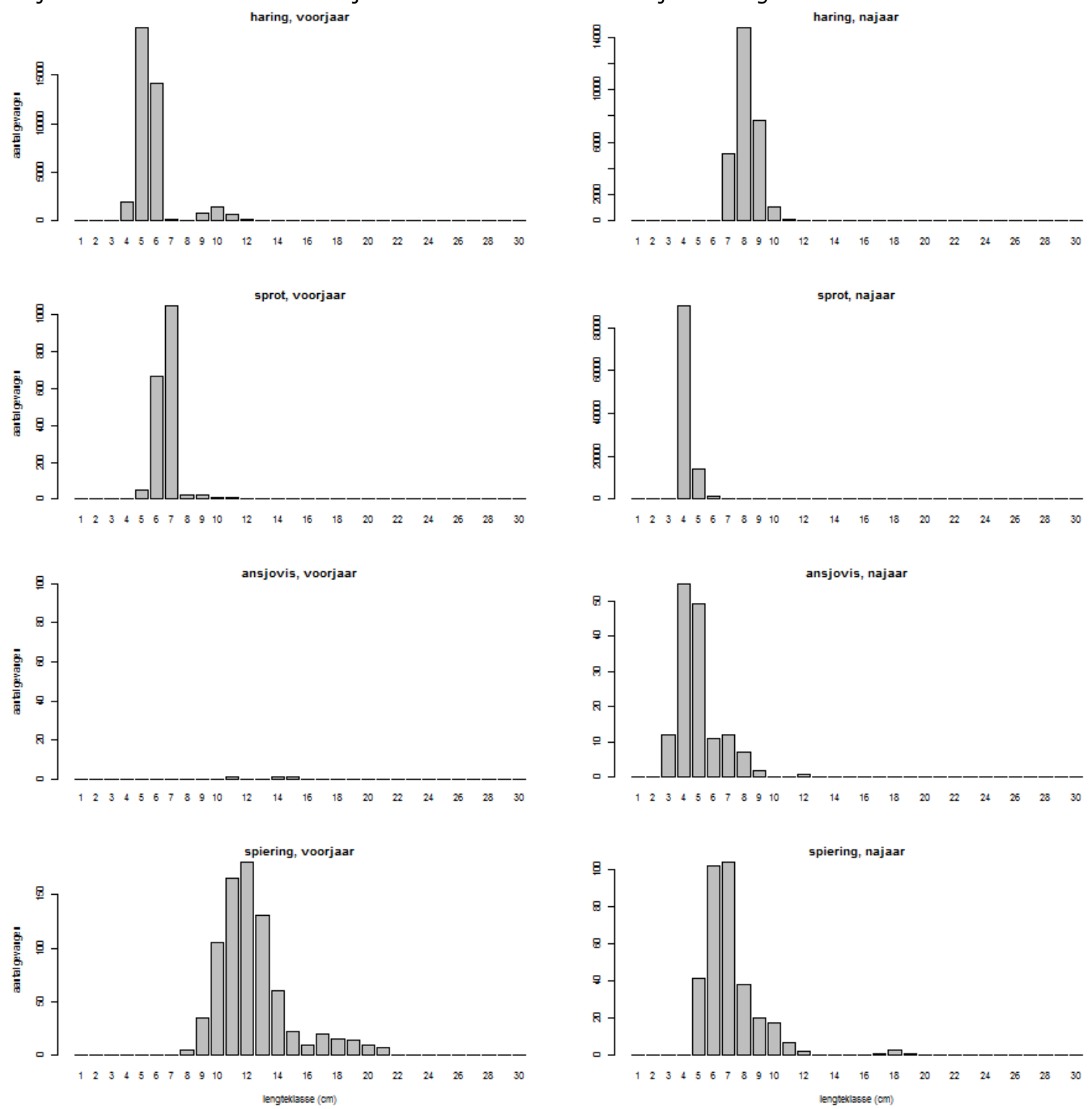

Figuur 2 Lengte frequentie van pelagische vissoorten in 2018. 


\subsubsection{Overige vissoorten}

Opvallend is in 2018 de relatief grote spreiding in de lengte van kleine zandspiering (Figuur 3). Koornaarvis heeft in zowel voor- als najaar globaal gezien dezelfde lengteverdeling. In het najaar 2018 is geen wijting en geen rivierprik gevangen. Van de laatste soort is dat zeer vermoedelijk omdat de bemonsteringsperiode buiten de trekperiode van rivierprik valt. Het gebrek aan wijting kan veroorzaakt worden door het verleggen van de ebstations bij Borssele, waar in het voorjaar de grootste hoeveelheid wijting is gevangen op de ebstroom.
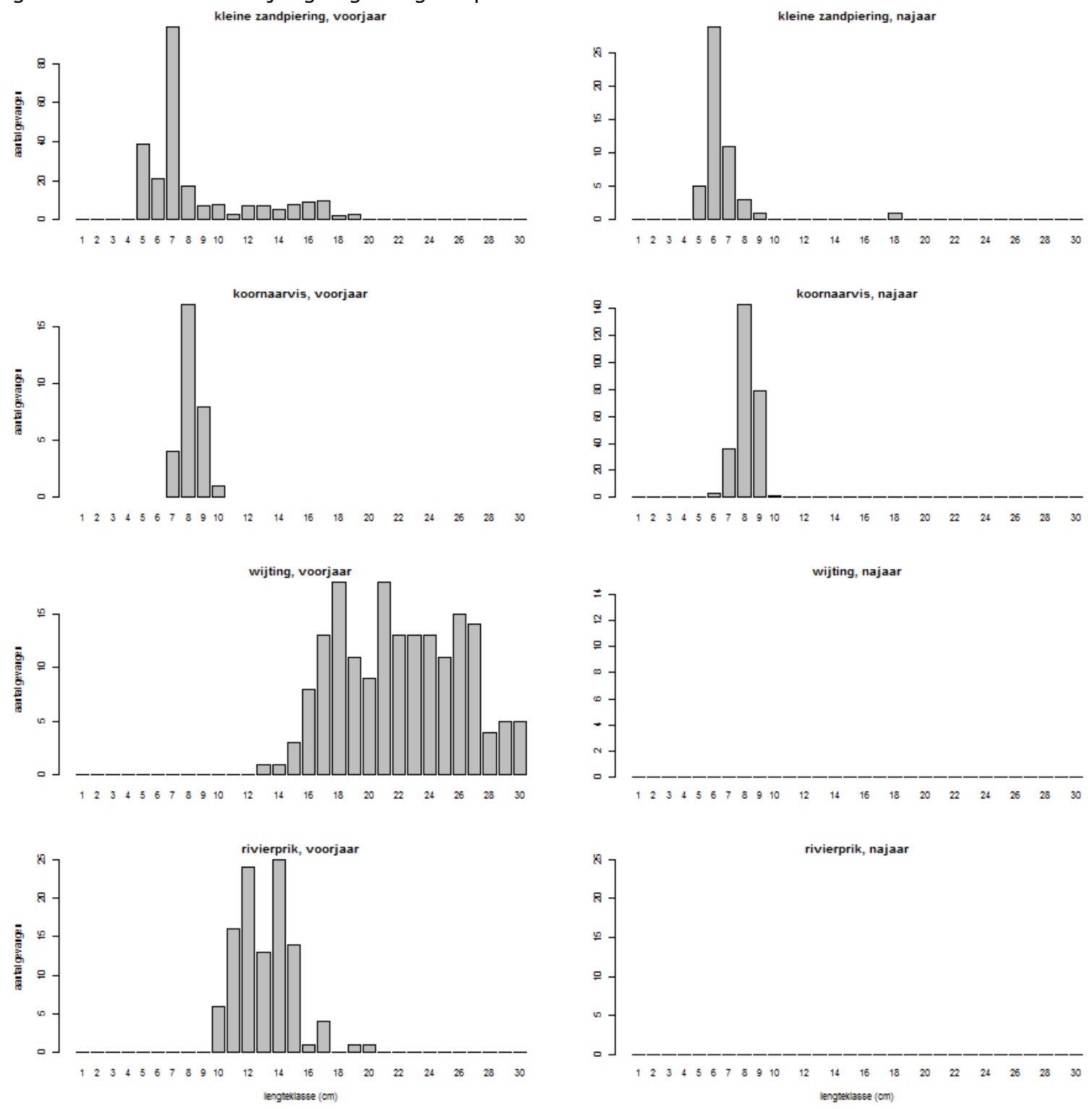

Figuur 3 Lengte-frequentie van een aantal vissoorten in 2018. 


\subsection{Resultaten 2008-2018}

Voor de vergelijking tussen de jaren is gebruik gemaakt van de periode 2008-2018, omdat sinds 2008 in mei en september wordt gemonsterd. In 2007 is de bemonstering uitgevoerd in juli en september, waarmee de vergelijking beïnvloed zou kunnen worden door de wisseling in bemonsteringsseizoen. Ten behoeve van de vergelijking over de jaren zijn soorten die niet in alle jaren tot op de soort zijn geïdentificeerd, samengevoegd. Dit geldt voor zandspiering, koornaarvissen, grondels en voor zeenaalden die niet met zekerheid als grote zeenaald zijn gedetermineerd.

\subsubsection{Gegevens per seizoen}

Op het eerste gezicht zijn geen duidelijke patronen in de tijd voor wat betreft aantalsontwikkeling te herkennen per seizoen (Figuur 4a, Figuur 4b). De vangsten van fint in het voorjaar lijken na een aantal jaren afname in 2018 een beetje toe te nemen. De vangst van zeeforel lijkt gestaag toe te nemen. De tijdserie voor de vier locaties gezamenlijk is echter nog te kort om trendanalyses op uit te voeren om dit statistisch te bevestigen. Een aantal soorten wordt voornamelijk in één seizoen aangetroffen. In het voorjaar zijn dat de diadrome vissoorten rivierprik, zeeforel en bot en in het najaar ansjovis en koornaarvis.
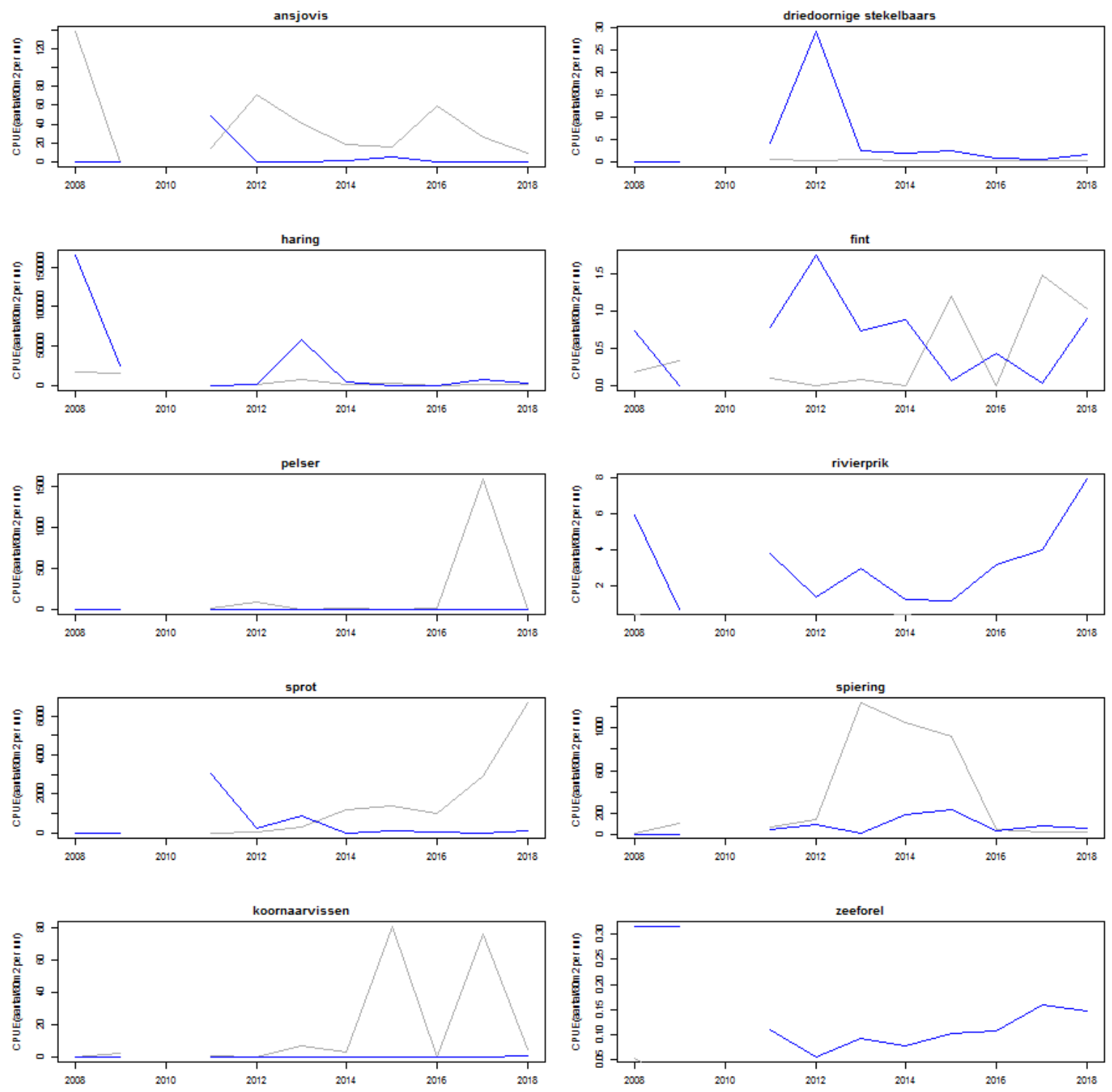

Figuur 4a Gegevens over de jaren in voor- (blauw) en najaar (grijs) voor een aantal frequent gevangen soorten. 2010: geen bemonstering. NB: de aantallen haring e/o sprot in 2008 zijn een onderschatting van de totale hoeveelheid Clupeiden die in dat jaar aanwezig waren. In dat jaar is ongeveer de helft van de 5-7 cm grote haring/sprot niet verder op naam gebracht dan Clupeiden. 

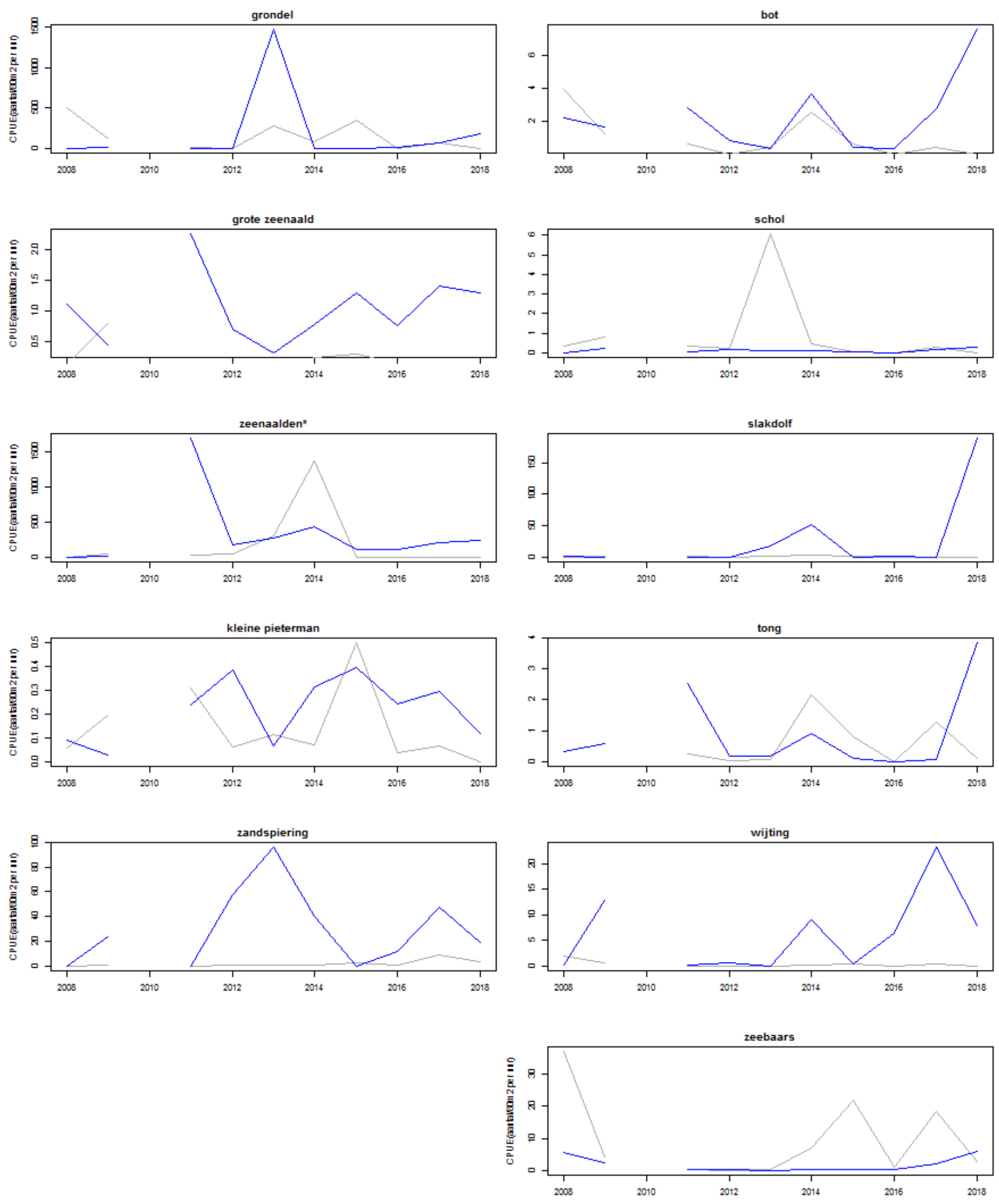

Figuur 4b Gegevens over de jaren in voor- (blauw) en najaar (grijs) voor een aantal frequent gevangen soorten. 2010: geen bemonstering

*dit betreft kleine exemplaren van de grote zeenaald en exemplaren van de kleine zeenaald 


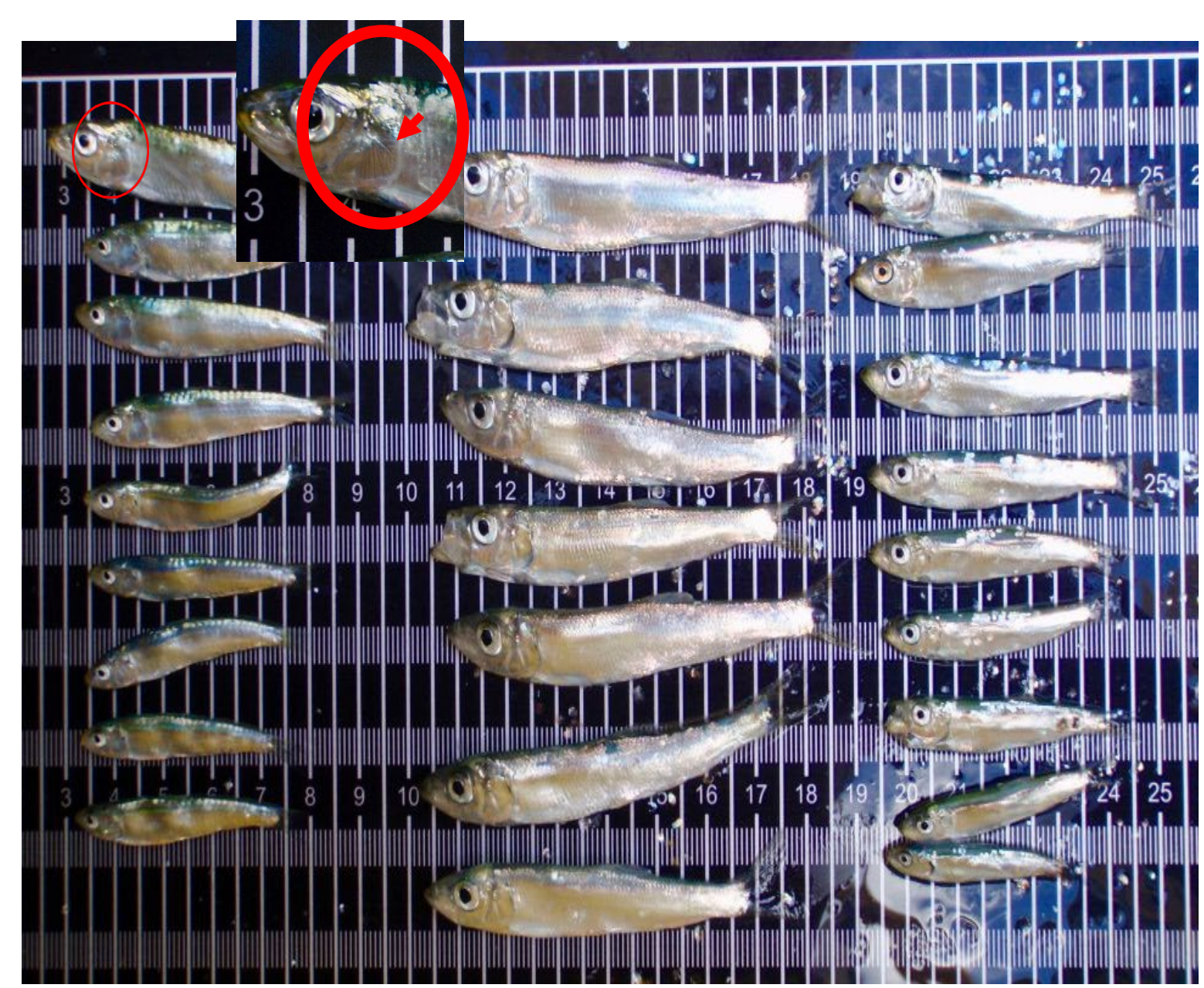

Gemengde vangst bij Paulinapolder, najaar 2018. Het linker rijtje is pelser (grote schubben, radiale groeven op de kieuwdeksel, zie inzet), middelste rijtje is haring, rechter rijtje is sprot. (Foto: $B$. Couperus)

\subsubsection{Gegevens per locatie}

De vangsten (cpue) per jaar per soort staan per locatie weergegeven in Bijlage 1. Sinds 2012 zijn alle vier de locaties bemonsterd. In de periode 2012-2018 zijn op het eerste gezicht weinig patronen te herkennen in de gevangen soorten en de aantallen ervan per locatie. Geep is in die jaren alleen bij Borssele en Paulinapolder aangetroffen en schar alleen bij Borssele. 


\section{$5 \quad$ Discussie en conclusies}

Het estuarium van de Westerschelde is een dynamisch ecosysteem met grote veranderingen in de geomorfologie, soms natuurlijk maar meestal door menselijk ingrijpen. Dit heeft zijn weerslag op de vangsten van met name pelagische vissoorten over de jaren.

De resultaten bevestigen dat de ankerkuil vooral geschikt is voor de bemonstering van pelagische vissoorten. De hoeveelheid ribkwallen in het voor- en najaar is opvallend en levert vangsten met een groot volume op alhoewel deze vangsten in verhouding maar een beperkte hoeveelheid vis opleveren. In sommige gevallen is ervoor gekozen om het net iets minder lang te laten staan om te voorkomen dat het vangstvolume te groot zou worden om de visnamigheid op peil te houden en om de vangst goed te kunnen verwerken. In 2018 is een extreme vangst met aasgarnalen gedaan bij Borssele (voorjaar, met vloed). Mede hierdoor werd een extreme hoeveelheid slakdolf gevangen in diezelfde trek; de aasgarnalen zorgden ervoor dat de slakdolf niet zonder meer door de mazen van het net kon.

In september 2018 was het doodtij (weinig tijverschil) tijdens de bemonstering. Het effect daarvan op de vangsten is onduidelijk, maar mogelijk wel aanwezig.

\subsection{Mogelijke verdere analyses}

Het effect van de maanfase (resulterend in doodtij, springtij of periodes waarin het tijverschil daar tussenin ligt) op de vangsten kan wellicht uitgezocht worden door tijdreeksen van zowel Westerschelde als Eems-Dollard te analyseren en effecten van de maanfase mee te nemen.

Om te beoordelen wat het effect van het gebruik van stroommeterstanden in plaats trekduur op de berekening van gestandaardiseerde vangsten heeft is een gedegen vergelijking van beide berekeningsmethodieken over de tijdserie noodzakelijk. 


\section{$6 \quad$ Kwaliteitsborging}

\subsection{Determinatie van soorten}

Op 16 januari 2018 hebben medewerkers van WMR de kans gekregen om een determinatietoets voor demersale vis en benthos te doen (de Boois, 2018) en op 23 november 2017 een toets voor pelagische vissoorten. De reisleiders van de ankerkuilbemonstering hebben beiden deze toetsen gedaan en met goed gevolg afgelegd.

\subsection{Wageningen Marine Research kwaliteitsmanagement}

Wageningen Marine Research beschikt over een ISO 9001:2015 gecertificeerd kwaliteitsmanagementsysteem. Dit certificaat is geldig tot 15 december 2021. De organisatie is gecertificeerd sinds 27 februari 2001. De certificering is uitgevoerd door DNV GL. 


\section{Literatuur}

Boois, I.J. de, 2018. Species identification workshop 2018: demersal fish and macro-zoobenthos. WMR internal report 18.002 .

Goudswaard P.C. \& I.J. de Boois 2007. Vismonitoring overgangswater: Westerschelde en Zoute Meren: Veerse Meer en Grevelingen. IMARES rapport C108/07.Broekhoven, G. and H. Savenije. 2012. Moving forward with forest governance, ETFRN news; issue no. 53. Wageningen: Tropenbos International. 


\section{Verantwoording}

Rapport C085/18

Projectnummer: 4316100124

Dit rapport is met grote zorgvuldigheid tot stand gekomen. De wetenschappelijke kwaliteit is intern getoetst door een collega-onderzoeker en het verantwoordelijk lid van het managementteam van Wageningen Marine Research

Akkoord:

Joep de Leeuw

Senior onderzoeker

Handtekening:

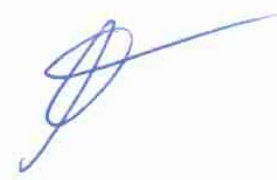

Datum:

17 december 2018

Akkoord:

Jakob Asjes

Manager Integratie

Handtekening:

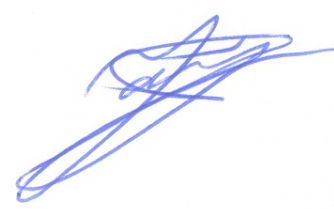

Datum:

17 december 2018 


\section{Bijlage 1 Gegevens per locatie 2008-2018}

Aantal gevangen per $80 \mathrm{~m}^{2}$ per uur; $\mathrm{x}=$ geen bemonstering uitgevoerd 


\section{Borssele}

\begin{tabular}{|c|c|c|c|c|c|c|c|c|c|c|c|c|}
\hline BORSSELE & & 2008 & 2009 & 2010 & 2011 & 2012 & 2013 & 2014 & 2015 & 2016 & 2017 & 2018 \\
\hline Aal & Anguilla anguilla & $x$ & $x$ & $x$ & $x$ & 0 & 0.1 & 0 & 0 & 0 & 0 & 0 \\
\hline Adderzeenaald & Entelurus aequoreus & $x$ & $x$ & $\mathrm{x}$ & $x$ & 0 & 0 & 0 & 0 & 0 & 0 & 0 \\
\hline Ansjovis & Engraulis encrasicolus & $x$ & $x$ & $x$ & $x$ & 72.1 & 13.9 & 3.7 & 10 & 1.7 & 2.3 & 11.1 \\
\hline Baars & Perca fluviatilis & $x$ & $x$ & $x$ & $x$ & 0 & 0 & 0 & 0 & 0 & 0 & 0 \\
\hline Bot & Platichthys flesus & $x$ & $x$ & $x$ & $x$ & 0.2 & 0.9 & 9.1 & 0.3 & 0.1 & 1.5 & 2.6 \\
\hline Botervis & Pholis gunnellus & $x$ & $x$ & $x$ & $x$ & 0 & 0 & 0 & 0 & 0 & 0 & 0.1 \\
\hline Brakwatergrondel & Pomatoschistus microps & $x$ & $x$ & $x$ & $\mathrm{x}$ & 0.2 & 0 & 0 & 0 & 0 & 0 & 0 \\
\hline Brasem & Abramis brama & $\mathrm{x}$ & $\mathrm{x}$ & $\mathrm{x}$ & $\mathrm{x}$ & 0 & 0 & 0 & 0 & 0 & 0 & 0 \\
\hline Clupeidae & Clupeidae & $x$ & $x$ & $x$ & $x$ & 0 & 0 & 0 & 0 & 0 & 0 & 0 \\
\hline Diklipharder & Chelon labrosus & $\mathrm{x}$ & $x$ & $x$ & $x$ & 0 & 0 & 0 & 0.1 & 0 & 0 & 0 \\
\hline Driedoornige stekelbaars & Gasterosteus aculeatus & $\mathrm{x}$ & $x$ & $x$ & $x$ & 44.5 & 1.5 & 0.5 & 0.6 & 0.1 & 0.1 & 0.5 \\
\hline Dunlipharder & Liza ramada & $x$ & $x$ & $x$ & $x$ & 0 & 0 & 0.3 & 0 & 0 & 0 & 0 \\
\hline Dwergtong & Buglossidium luteum & $x$ & $x$ & $x$ & $x$ & 0 & 0 & 0.1 & 0 & 0 & 0 & 0 \\
\hline Fint & Alosa fallax & $\mathrm{x}$ & $x$ & $x$ & $x$ & 0 & 0 & 0 & 0 & 0.2 & 0.4 & 0 \\
\hline Geep & Belone belone & $\mathrm{x}$ & $x$ & $x$ & $x$ & 0 & 0 & 0 & 0.2 & 0 & 0.2 & 0.1 \\
\hline Glasgrondel & Aphia minuta & $x$ & $x$ & $x$ & $x$ & 0.4 & 0 & 1.4 & 0.5 & 0 & 1.4 & 0 \\
\hline Goudharder & Liza aurata & $x$ & $x$ & $x$ & $x$ & 0 & 0 & 0 & 0 & 0 & 0 & 0 \\
\hline Grauwe poon & Eutrigla gurnardus & $x$ & $x$ & $x$ & $x$ & 0.1 & 0.1 & 0.5 & 0.1 & 0 & 0 & 0 \\
\hline Groene zeedonderpad & Taurulus bubalis & $x$ & $x$ & $x$ & $\mathrm{x}$ & 0.1 & 0 & 0 & 0 & 0 & 0 & 0 \\
\hline Grondel & Pomatoschistus sp. & $x$ & $x$ & $x$ & $x$ & 0.2 & 240 & 92.7 & 343 & 0.2 & 181 & 226 \\
\hline Grote zeenaald & Syngnathus acus & $\mathrm{x}$ & $x$ & $x$ & $\mathrm{x}$ & 0.3 & 0.2 & 1.6 & 1.5 & 0.6 & 1 & 0.9 \\
\hline Harder ongespecificeerd & Mugilidae & $x$ & $x$ & $x$ & $\mathrm{x}$ & 0 & 0 & 0 & 0 & 0 & 0.9 & 0 \\
\hline Haring & Clupea harengus & $x$ & $\mathrm{x}$ & $\mathrm{x}$ & $x$ & 386 & 42846 & 3505 & 180 & 188 & 557 & 584 \\
\hline Harnasmannetje & Agonus cataphractus & $x$ & $x$ & $x$ & $x$ & 0.1 & 0.2 & 1.3 & 0.5 & 0.1 & 0.5 & 0 \\
\hline Horsmakreel & Trachurus trachurus & $\mathrm{x}$ & $x$ & $\mathrm{x}$ & $x$ & 0.1 & 0.2 & 0 & 0 & 0 & 0.1 & 0 \\
\hline Kabeljauw & Gadus morhua & $x$ & $x$ & $x$ & $x$ & 0.1 & 0 & 0 & 0 & 0 & 0 & 0 \\
\hline Kleine pieterman & Echiichthys vipera & $x$ & $x$ & $x$ & $x$ & 0.1 & 0 & 0.2 & 0 & 0.1 & 0.1 & 0 \\
\hline Kleine zandspiering & Ammodytes tobianus & $\mathrm{x}$ & $\mathrm{x}$ & $x$ & $x$ & 1.8 & 1.4 & 0.3 & 1.1 & 0.1 & 1.7 & 13.3 \\
\hline Kleine zeenaald & Syngnathus rostellatus & $\mathrm{x}$ & $x$ & $x$ & $x$ & 15.7 & 88.3 & 174 & 11.7 & 7.5 & 3.4 & 87.6 \\
\hline Koornaarvissen & Atherina sp. & $\mathrm{x}$ & $x$ & $x$ & $x$ & 0.1 & 0 & 0.2 & 0.4 & 0.2 & 52.7 & 1 \\
\hline Kortsnuitzeepaardje & Hippocampus hippocampus & $x$ & $x$ & $x$ & $x$ & 0.1 & 0 & 0 & 0 & 0 & 0 & 0 \\
\hline Makreel & Scomber scombrus & $x$ & $x$ & $x$ & $x$ & 0 & 0 & 0 & 0 & 0 & 0 & 0 \\
\hline Pelser & Sardina pilchardus & $x$ & $x$ & $\mathrm{x}$ & $x$ & 124 & 0.1 & 3.9 & 0.2 & 0.3 & 5.3 & 0.3 \\
\hline Pitvis & Callionymus lyra & $x$ & $x$ & $x$ & $x$ & 0 & 0 & 0 & 0 & 0 & 0 & 0 \\
\hline Pontische stroomgrondel & Neogobius fluviatilis & $x$ & $x$ & $\mathrm{x}$ & $x$ & 0 & 0 & 0.1 & 0 & 0 & 0 & 0 \\
\hline Pos & Gymnocephalus cernuus & $x$ & $x$ & $x$ & $x$ & 0 & 0 & 0 & 0 & 0 & 0 & 0 \\
\hline Puitaal & Zoarces viviparus & $x$ & $x$ & $x$ & $x$ & 0 & 0 & 0 & 0 & 0 & 0 & 0 \\
\hline Rivierprik & Lampetra fluviatilis & $x$ & $x$ & $x$ & $x$ & 0.6 & 0.8 & 0.8 & 0.5 & 0.3 & 0.6 & 3.8 \\
\hline Rode poon & Chelidonichthys lucerna & $x$ & $\mathrm{x}$ & $x$ & $x$ & 0 & 0.4 & 0.1 & 0.3 & 0 & 0.3 & 0.4 \\
\hline Schar & Limanda limanda & $\mathrm{x}$ & $x$ & $x$ & $x$ & 0.1 & 0.2 & 0 & 0.2 & 0.1 & 0.5 & 0.1 \\
\hline Schol & Pleuronectes platessa & $x$ & $x$ & $x$ & $x$ & 0.2 & 10.6 & 0.4 & 0.1 & 0 & 0.3 & 0.2 \\
\hline Schurftvis & Arnoglossus laterna & $\mathrm{x}$ & $x$ & $x$ & $x$ & 0 & 0 & 0.1 & 0 & 0 & 0 & 0.1 \\
\hline Slakdolf & Liparis liparis liparis & $\mathrm{x}$ & $x$ & $\mathrm{x}$ & $x$ & 0.2 & 30.6 & 107 & 2.7 & 0.1 & 0.2 & 379 \\
\hline Smelt & Hyperoplus lanceolatus & $\mathrm{x}$ & $x$ & $x$ & $x$ & 0 & 1.5 & 0 & 0 & 0.1 & 0 & 0 \\
\hline Snoekbaars & Sander lucioperca & $x$ & $x$ & $x$ & $\mathrm{x}$ & 0 & 0 & 0 & 0 & 0 & 0 & 0 \\
\hline Snotolf & Cyclopterus lumpus & $x$ & $x$ & $x$ & $x$ & 0 & 0 & 0.1 & 0.3 & 0 & 0 & 0 \\
\hline Spiering & Osmerus eperlanus & $x$ & $x$ & $x$ & $x$ & 14 & 566 & 144 & 143 & 11.7 & 56.5 & 22 \\
\hline Sprot & Sprattus sprattus & $x$ & $x$ & $x$ & $x$ & 23 & 154 & 172 & 175 & 527 & 222 & 2161 \\
\hline Steenbolk & Trisopterus luscus & $x$ & $x$ & $x$ & $x$ & 2 & 1.7 & 67.3 & 2.2 & 0.2 & 107 & 7.5 \\
\hline Stekelrog & Raja clavata & $x$ & $x$ & $x$ & $x$ & 0 & 0 & 0 & 0 & 0 & 0 & 0 \\
\hline Tong & Solea solea & $x$ & $x$ & $x$ & $x$ & 0 & 0.4 & 5.7 & 1.6 & 0 & 0.2 & 1.5 \\
\hline Vierdradige meun & Enchelyopus cimbrius & $x$ & $x$ & $x$ & $\mathrm{x}$ & 0 & 0 & 0 & 0 & 0 & 0 & 0 \\
\hline Vijfdradige meun & Ciliata mustela & $x$ & $x$ & $x$ & $\mathrm{x}$ & 0 & 0 & 0.2 & 0 & 0 & 0 & 0 \\
\hline Vorskwab & Raniceps raninus & $x$ & $x$ & $x$ & $x$ & 0 & 0 & 0 & 0 & 0 & 0 & 0 \\
\hline Wijting & Merlangius merlangus & $x$ & $x$ & $x$ & $x$ & 0.4 & 0.1 & 8.9 & 1.1 & 6.7 & 39.9 & 12.3 \\
\hline Zalm & Salmo salar & $\mathrm{x}$ & $x$ & $x$ & $x$ & 0 & 0 & 0.1 & 0 & 0 & 0 & 0 \\
\hline Zandspieringen indet. & Ammodytes sp. & $\mathrm{x}$ & $x$ & $x$ & $x$ & 0 & 0 & 0 & 0 & 0 & 0 & 0 \\
\hline Zeebaars & Dicentrarchus labrax & $x$ & $x$ & $x$ & $x$ & 0.5 & 0.2 & 4.6 & 3.5 & 0.6 & 1.2 & 1.3 \\
\hline Zeedonderpad & Myoxocephalus scorpius & $\mathrm{x}$ & $x$ & $x$ & $x$ & 0 & 0.3 & 0.6 & 0 & 0 & 0 & 0 \\
\hline Zeeforel & Salmo trutta trutta & $\mathrm{x}$ & $x$ & $x$ & $x$ & 0 & 0.1 & 0 & 0.1 & 0 & 0 & 0 \\
\hline Zeenaalden indet. & Syngnathus sp. & $x$ & $x$ & $x$ & $x$ & 0 & 0 & 0 & 0 & 0 & 0.2 & 0 \\
\hline Zeeprik & Petromyzon marinus & $x$ & $x$ & $x$ & $x$ & 0 & 0 & 0 & 0 & 0 & 0 & 0 \\
\hline vislarven & larvae Pisces & $\mathrm{x}$ & $\mathrm{x}$ & $\mathrm{x}$ & $\mathrm{x}$ & 0 & 0 & 0 & 213 & 48655 & 69972 & 10843 \\
\hline
\end{tabular}




\section{Brouwersplaat}

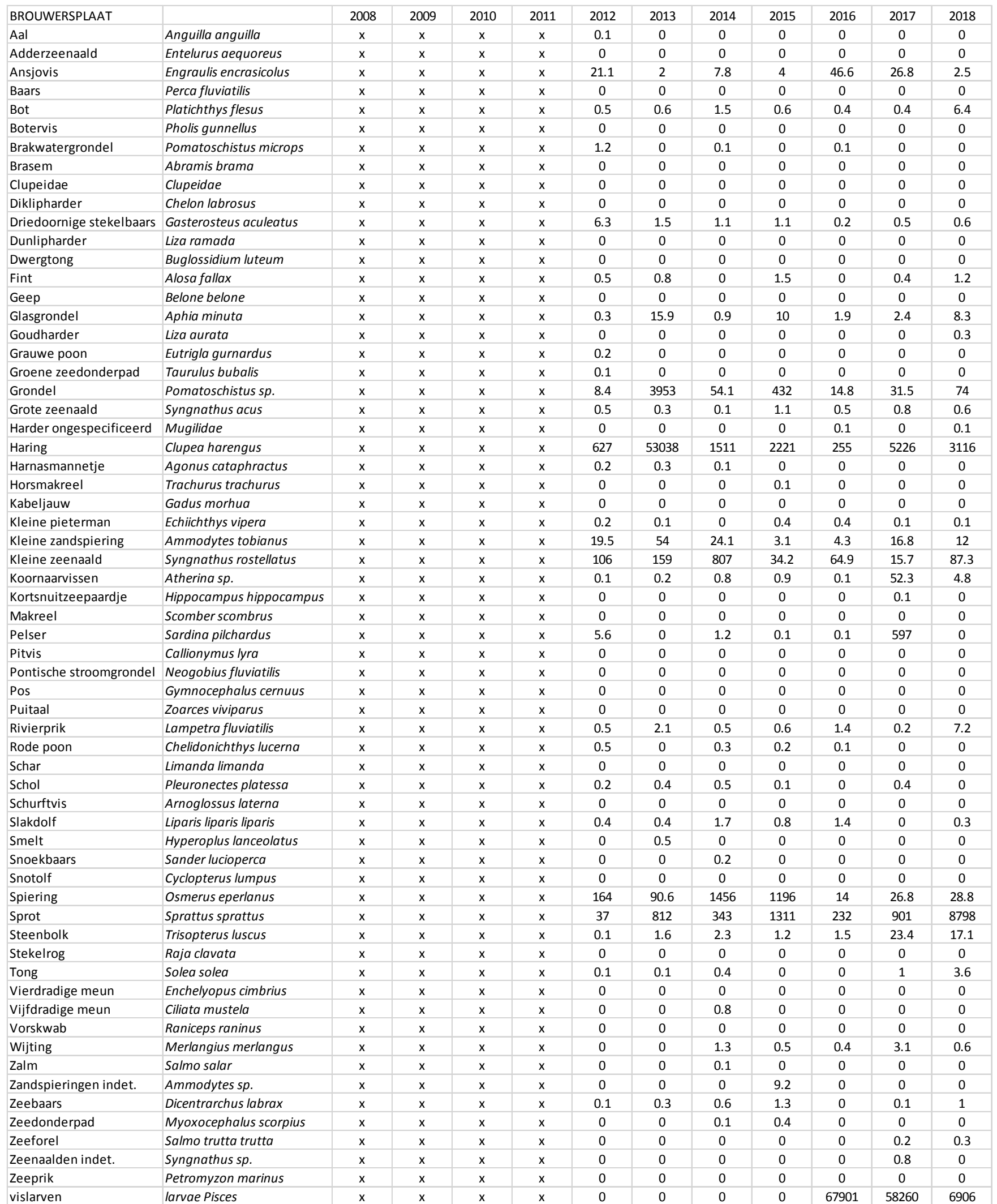




\section{Paulinapolder}

\begin{tabular}{|c|c|c|c|c|c|c|c|c|c|c|c|c|}
\hline PAULINAPOLDER & & 2008 & 2009 & 2010 & 2011 & 2012 & 2013 & 2014 & 2015 & 2016 & 2017 & 2018 \\
\hline Aal & Anguilla anguilla & 0.1 & 0 & $x$ & 0 & 0 & 0 & 0 & 0 & 0 & 0 & 0 \\
\hline Adderzeenaald & Entelurus aequoreus & 0 & 0 & $x$ & 0 & 0 & 0 & 0 & 0 & 0 & 0 & 0 \\
\hline Ansjovis & Engraulis encrasicolus & 51.8 & 0.7 & $x$ & 66.5 & 6 & 9.6 & 15.8 & 28.1 & 10.1 & 21.1 & 3.5 \\
\hline Baars & Perca fluviatilis & 0 & 0 & $x$ & 0 & 0 & 0 & 0 & 0 & 0 & 0 & 0 \\
\hline Bot & Platichthys flesus & 1.9 & 1.3 & $x$ & 0 & 0.7 & 0 & 0.9 & 0.8 & 0.1 & 1.2 & 3.5 \\
\hline Botervis & Pholis gunnellus & 0 & 0 & $x$ & 0 & 0 & 0 & 0 & 0 & 0 & 0 & 0 \\
\hline Brakwatergrondel & Pomatoschistus microps & 0 & 0 & $x$ & 0 & 0 & 0 & 0 & 0 & 0 & 0 & 0 \\
\hline Brasem & Abramis brama & 0 & 0 & $x$ & 0 & 0 & 0 & 0 & 0 & 0 & 0 & 0 \\
\hline Clupeidae & Clupeidae & 356179 & 0 & $x$ & 0 & 0 & 0 & 0 & 0 & 0 & 0 & 0 \\
\hline Diklipharder & Chelon labrosus & 0 & 0 & $x$ & 0 & 0 & 0 & 0 & 0 & 0 & 0 & 0 \\
\hline Driedoornige stekelbaars & Gasterosteus aculeatus & 0 & 0 & $x$ & 0.1 & 7.7 & 1.3 & 1.5 & 1.3 & 0.5 & 0.1 & 0.2 \\
\hline Dunlipharder & Liza ramada & 0.1 & 0 & $x$ & 0 & 0 & 0 & 2 & 0.1 & 0 & 0 & 0.2 \\
\hline Dwergtong & Buglossidium luteum & 0 & 0 & $\mathrm{x}$ & 0 & 0 & 0 & 0 & 0 & 0 & 0 & 0 \\
\hline Fint & Alosa fallax & 0 & 0.3 & $x$ & 0 & 0 & 0 & 0.1 & 0.2 & 0 & 1.8 & 0 \\
\hline Geep & Belone belone & 0 & 0 & $x$ & 0 & 0.2 & 0.1 & 0.2 & 0.2 & 0.2 & 0.1 & 0.1 \\
\hline Glasgrondel & Aphia minuta & 0 & 0.5 & $x$ & 0.1 & 0.1 & 11.2 & 2.1 & 17 & 0.2 & 2.1 & 0.1 \\
\hline Goudharder & Liza aurata & 1.9 & 0.4 & $x$ & 0 & 0 & 0 & 0 & 0.4 & 0 & 0 & 0.2 \\
\hline Grauwe poon & Eutrigla gurnardus & 0 & 0 & $x$ & 0 & 0 & 0.1 & 0 & 0 & 0 & 0 & 0 \\
\hline Groene zeedonderpad & Taurulus bubalis & 0 & 0 & $x$ & 0 & 0 & 0 & 0 & 0 & 0 & 0 & 0 \\
\hline Grondel & Pomatoschistus sp. & 349 & 72.7 & $x$ & 0.4 & 0 & 240 & 20.4 & 9.5 & 0.7 & 68.1 & 11.1 \\
\hline Grote zeenaald & Syngnathus acus & 0.6 & 0.2 & $\mathrm{x}$ & 0.4 & 0.1 & 0.1 & 0.3 & 0.1 & 0.5 & 0.5 & 0.1 \\
\hline Harder ongespecificeerd & Mugilidae & 0 & 0 & $x$ & 0 & 0 & 0 & 0 & 0 & 0.2 & 0.1 & 0.1 \\
\hline Haring & Clupea harengus & 173187 & 24839 & $\mathrm{x}$ & 36.7 & 2201 & 43648 & 1369 & 754 & 42 & 11989 & 3573 \\
\hline Harnasmannetje & Agonus cataphractus & 0 & 0 & $x$ & 0 & 0 & 0 & 0 & 0 & 0 & 0 & 0 \\
\hline Horsmakreel & Trachurus trachurus & 0.1 & 0 & $x$ & 0.1 & 0.1 & 1.3 & 0 & 0 & 0 & 0.1 & 0 \\
\hline Kabeljauw & Gadus morhua & 0.2 & 0.2 & $\mathrm{x}$ & 0 & 0 & 0 & 0 & 0 & 0.3 & 0 & 0 \\
\hline Kleine pieterman & Echiichthys vipera & 0 & 0.1 & $\mathrm{x}$ & 0 & 0.4 & 0.2 & 0.6 & 0.6 & 0 & 0.4 & 0.2 \\
\hline Kleine zandspiering & Ammodytes tobianus & 0 & 12.6 & $x$ & 0 & 82.5 & 94.5 & 7.7 & 0.9 & 3.2 & 70.4 & 4.4 \\
\hline Kleine zeenaald & Syngnathus rostellatus & 0 & 3.2 & $\mathrm{x}$ & 18 & 22.9 & 15.6 & 75.4 & 58.5 & 8 & 1.5 & 62.3 \\
\hline Koornaarvissen & Atherina sp. & 0.1 & 2.2 & $x$ & 0.5 & 0.1 & 11.2 & 4.2 & 159 & 0.2 & 30 & 0.2 \\
\hline Kortsnuitzeepaardje & Hippocampus hippocampus & 0 & 0 & $x$ & 0 & 0 & 0 & 0 & 0 & 0 & 0 & 0 \\
\hline Makreel & Scomber scombrus & 8.6 & 0 & $x$ & 0.1 & 0 & 0 & 0 & 0 & 0 & 0 & 0 \\
\hline Pelser & Sardina pilchardus & 0 & 0.1 & $x$ & 13.1 & 37.8 & 1.5 & 23 & 0.3 & 13.8 & 2600 & 7.9 \\
\hline Pitvis & Callionymus lyra & 0 & 0 & $x$ & 0 & 0 & 0 & 0 & 0 & 0 & 0 & 0 \\
\hline Pontische stroomgrondel & Neogobius fluviatilis & 0 & 0 & $x$ & 0 & 0 & 0 & 0 & 0 & 0 & 0 & 0 \\
\hline Pos & Gymnocephalus cernuus & 0 & 0 & $x$ & 0 & 0 & 0 & 0 & 0 & 0 & 0 & 0 \\
\hline Puitaal & Zoarces viviparus & 0 & 0.1 & $x$ & 0 & 0 & 0 & 0 & 0 & 0 & 0 & 0 \\
\hline Rivierprik & Lampetra fluviatilis & 0.1 & 0 & $x$ & 0 & 0.1 & 0.3 & 0.1 & 0.4 & 0.3 & 0.1 & 2.3 \\
\hline Rode poon & Chelidonichthys lucerna & 0 & 0.1 & $x$ & 0 & 0 & 0 & 0.1 & 0.2 & 0 & 0 & 0 \\
\hline Schar & Limanda limanda & 0 & 0.1 & $x$ & 0 & 0 & 0 & 0 & 0 & 0 & 0 & 0 \\
\hline Schol & Pleuronectes platessa & 0.2 & 0.5 & $x$ & 0 & 0.1 & 0 & 0.1 & 0 & 0 & 0.1 & 0 \\
\hline Schurftvis & Arnoglossus laterna & 0 & 0 & $x$ & 0 & 0 & 0 & 0 & 0 & 0 & 0 & 0 \\
\hline Slakdolf & Liparis liparis liparis & 0.1 & 0.4 & $x$ & 0 & 0 & 0.2 & 0.2 & 0 & 0 & 0 & 0 \\
\hline Smelt & Hyperoplus lanceolatus & 0 & 0 & $x$ & 0.5 & 1.3 & 40 & 0.1 & 0.2 & 0 & 0.3 & 0 \\
\hline Snoekbaars & Sander lucioperca & 0 & 0 & $\mathrm{x}$ & 0 & 0 & 0 & 0 & 0 & 0 & 0 & 0 \\
\hline Snotolf & Cyclopterus lumpus & 0 & 0 & $x$ & 0 & 0 & 0.1 & 0 & 0.1 & 0 & 0 & 0 \\
\hline Spiering & Osmerus eperlanus & 0.2 & 0.6 & $x$ & 12 & 13.6 & 295 & 84.7 & 65.4 & 6.2 & 10.4 & 12.8 \\
\hline Sprot & Sprattus sprattus & 0 & 10.2 & $x$ & 4027 & 450 & 1232 & 1802 & 582 & 52.4 & 3730 & 221 \\
\hline Steenbolk & Trisopterus luscus & 1 & 1 & $x$ & 0.1 & 0.6 & 0 & 0.5 & 0.2 & 1.9 & 1.2 & 0.1 \\
\hline Stekelrog & Raja clavata & 0 & 0 & $x$ & 0 & 0 & 0 & 0 & 0 & 0 & 0 & 0 \\
\hline Tong & Solea solea & 1.5 & 1 & $x$ & 0 & 0 & 0.1 & 0 & 0.3 & 0 & 1.6 & 0.4 \\
\hline Vierdradige meun & Enchelyopus cimbrius & 0 & 0 & $x$ & 0 & 0 & 0 & 0 & 0 & 0 & 0 & 0 \\
\hline Vijfdradige meun & Ciliata mustela & 0.2 & 0 & $x$ & 0 & 0 & 0 & 0.2 & 0 & 0 & 0 & 0 \\
\hline Vorskwab & Raniceps raninus & 0 & 0.1 & $x$ & 0 & 0 & 0 & 0 & 0 & 0 & 0 & 0 \\
\hline Wijting & Merlangius merlangus & 1.6 & 13.1 & $\mathrm{x}$ & 0 & 0.4 & 0 & 8.4 & 0.1 & 5.6 & 4 & 2.8 \\
\hline Zalm & Salmo salar & 0 & 0 & $\mathrm{x}$ & 0 & 0 & 0 & 0 & 0 & 0 & 0 & 0 \\
\hline Zandspieringen indet. & Ammodytes sp. & 13.2 & 0 & $\mathrm{x}$ & 408 & 0 & 0 & 0 & 17.8 & 0 & 0 & 0 \\
\hline Zeebaars & Dicentrarchus labrax & 38.2 & 4.1 & $x$ & 0.2 & 0.6 & 0.6 & 9.5 & 39.3 & 2.7 & 38.3 & 7.8 \\
\hline Zeedonderpad & Myoxocephalus scorpius & 0.1 & 0 & $\mathrm{x}$ & 0 & 0.2 & 0 & 0 & 0 & 0 & 0 & 0 \\
\hline Zeeforel & Salmo trutta trutta & 0.2 & 0 & $x$ & 0.1 & 0 & 0 & 0.1 & 0.1 & 0.2 & 0.1 & 0 \\
\hline Zeenaalden indet. & Syngnathus sp. & 0 & 0 & $x$ & 0 & 0 & 0 & 0 & 0 & 0 & 0.1 & 0 \\
\hline Zeeprik & Petromyzon marinus & 0 & 0 & $x$ & 0 & 0 & 0 & 0 & 0 & 0 & 0 & 0 \\
\hline vislarven & larvae Pisces & 0 & 0 & $x$ & 0 & 0 & 0 & 0 & 71.9 & 58934 & 85294 & 20007 \\
\hline
\end{tabular}




\section{Valkenisse}

\begin{tabular}{|c|c|c|c|c|c|c|c|c|c|c|c|c|}
\hline VALKENISSE & & 2008 & 2009 & 2010 & 2011 & 2012 & 2013 & 2014 & 2015 & 2016 & 2017 & 2018 \\
\hline Aal & Anguilla anguilla & 0.1 & 0.1 & $x$ & 0.1 & 0 & 0 & 0 & 0 & 0 & 0 & 0 \\
\hline Adderzeenaald & Entelurus aequoreus & 0.1 & 0 & $x$ & 0 & 0 & 0 & 0 & 0 & 0 & 0 & 0 \\
\hline Ansjovis & Engraulis encrasicolus & 87.2 & 0.5 & $x$ & 10.3 & 43.6 & 47.3 & 11.2 & 2.6 & 59.7 & 3.6 & 2.8 \\
\hline Baars & Perca fluviatilis & 0.2 & 0 & $x$ & 0 & 0.1 & 0 & 0 & 0.1 & 0 & 0 & 0 \\
\hline Bot & Platichthys flesus & 4.3 & 1.7 & $\mathrm{x}$ & 3.4 & 0.5 & 0.3 & 0.8 & 0.6 & 0.1 & 3.4 & 2.8 \\
\hline Botervis & Pholis gunnellus & 0 & 0.1 & $x$ & 0 & 0 & 0 & 0 & 0 & 0 & 0 & 0.2 \\
\hline Brakwatergrondel & Pomatoschistus microps & 0 & 0 & $x$ & 6.7 & 2.8 & 0 & 0 & 0 & 0 & 0 & 0 \\
\hline Brasem & Abramis brama & 0 & 0 & $x$ & 0 & 0 & 0 & 0.2 & 0 & 0 & 0 & 0 \\
\hline Clupeidae & Clupeidae & 9833 & 0 & $x$ & 0 & 0 & 0 & 0 & 0 & 0 & 0 & 0 \\
\hline Diklipharder & Chelon labrosus & 0 & 0 & $\mathrm{x}$ & 0 & 0 & 0 & 0 & 0.1 & 0 & 0 & 0 \\
\hline Driedoornige stekelbaars & Gasterosteus aculeatus & 0 & 0 & $\mathrm{x}$ & 4.5 & 0.4 & 1.8 & 1.6 & 2.1 & 0.9 & 0.9 & 2.6 \\
\hline Dunlipharder & Liza ramada & 0 & 0 & $x$ & 0.1 & 0 & 0 & 0 & 0.2 & 0 & 0 & 0 \\
\hline Dwergtong & Buglossidium luteum & 0 & 0 & $x$ & 0 & 0 & 0 & 0 & 0 & 0 & 0 & 0 \\
\hline Fint & Alosa fallax & 0.9 & 0 & $x$ & 0.9 & 3 & 1 & 1.7 & 0.9 & 0.7 & 0.5 & 2.7 \\
\hline Geep & Belone belone & 0 & 0 & $x$ & 0 & 0 & 0 & 0 & 0 & 0 & 0 & 0 \\
\hline Glasgrondel & Aphia minuta & 54.9 & 0.5 & $x$ & 11.7 & 2.4 & 0 & 0 & 5.5 & 0.5 & 1.7 & 5.1 \\
\hline Goudharder & Liza aurata & 0.2 & 0 & $x$ & 0 & 0 & 0 & 0 & 0 & 0 & 0 & 0 \\
\hline Grauwe poon & Eutrigla gurnardus & 0 & 0 & $x$ & 0 & 0.2 & 0.1 & 0 & 0 & 0 & 0 & 0 \\
\hline Groene zeedonderpad & Taurulus bubalis & 0.1 & 0 & $x$ & 0 & 0 & 0 & 0 & 0 & 0 & 0 & 0 \\
\hline Grondel & Pomatoschistus sp. & 150 & 64.5 & $x$ & 4.9 & 0.9 & 20.3 & 1.8 & 1.8 & 0 & 0.5 & 41 \\
\hline Grote zeenaald & Syngnathus acus & 0.6 & 1 & $x$ & 2 & 0.5 & 0.2 & 0.1 & 0.6 & 0.2 & 0.8 & 1.4 \\
\hline Harder ongespecificeerd & Mugilidae & 0 & 0 & $x$ & 0 & 0 & 0 & 0 & 0 & 0.1 & 0.1 & 12.6 \\
\hline Haring & Clupea harengus & 10125 & 15262 & $x$ & 234 & 428 & 5230 & 4076 & 1095 & 367 & 343 & 640 \\
\hline Harnasmannetje & Agonus cataphractus & 7.9 & 0.1 & $\mathrm{x}$ & 0 & 0 & 0.1 & 0 & 0 & 0 & 0 & 0 \\
\hline Horsmakreel & Trachurus trachurus & 0 & 0 & $x$ & 0 & 0 & 0 & 0 & 0 & 0 & 0.1 & 0 \\
\hline Kabeljauw & Gadus morhua & 0.1 & 0.1 & $x$ & 0 & 0 & 0 & 0 & 0 & 0 & 0 & 0 \\
\hline Kleine pieterman & Echiichthys vipera & 0.1 & 0.1 & $x$ & 0.4 & 0.3 & 0.1 & 0 & 0.6 & 0.1 & 0.1 & 0 \\
\hline Kleine zandspiering & Ammodytes tobianus & 0 & 11.7 & $\mathrm{x}$ & 0 & 12.9 & 57.3 & 48.6 & 0.9 & 15.7 & 24.9 & 15.3 \\
\hline Kleine zeenaald & Syngnathus rostellatus & 0.2 & 53.8 & $x$ & 1702 & 306 & 851 & 2528 & 87.1 & 125 & 376 & 248 \\
\hline Koornaarvissen & Atherina $s p$. & 0 & 0.3 & $x$ & 0 & 0 & 0.9 & 0.2 & 2.1 & 0.1 & 16.8 & 4.3 \\
\hline Kortsnuitzeepaardje & Hippocampus hippocampus & 0 & 0 & $x$ & 0 & 0 & 0 & 0 & 0 & 0 & 0 & 0 \\
\hline Makreel & Scomber scombrus & 0 & 0 & $x$ & 0 & 0.1 & 0 & 0 & 0 & 0 & 0 & 0 \\
\hline Pelser & Sardina pilchardus & 0 & 0 & $x$ & 0.2 & 4.5 & 0 & 0 & 0 & 0.1 & 0 & 0 \\
\hline Pitvis & Callionymus lyra & 0 & 0 & $x$ & 0 & 0 & 0 & 0 & 0 & 0 & 0 & 0 \\
\hline Pontische stroomgrondel & Neogobius fluviatilis & 0 & 0 & $\mathrm{x}$ & 0 & 0 & 0 & 0 & 0 & 0 & 0 & 0 \\
\hline Pos & Gymnocephalus cernuus & 0 & 0 & $\mathrm{x}$ & 0 & 0 & 0.1 & 0 & 0 & 0 & 0 & 0 \\
\hline Puitaal & Zoarces viviparus & 0 & 0 & $x$ & 0 & 0 & 0 & 0 & 0 & 0 & 0 & 0 \\
\hline Rivierprik & Lampetra fluviatilis & 6.2 & 0.9 & $x$ & 3.9 & 1.7 & 3.9 & 1.9 & 1.1 & 4.4 & 7.2 & 2.6 \\
\hline Rode poon & Chelidonichthys lucerna & 0.1 & 0.1 & $\mathrm{x}$ & 0.3 & 0.6 & 0 & 0 & 0 & 0.1 & 0 & 0.6 \\
\hline Schar & Limanda limanda & 0 & 0.5 & $\mathrm{x}$ & 0 & 0 & 0 & 0 & 0 & 0 & 0 & 0 \\
\hline Schol & Pleuronectes platessa & 0.1 & 0.5 & $x$ & 0.3 & 0.2 & 0 & 0 & 0 & 0 & 0 & 0.3 \\
\hline Schurftvis & Arnoglossus laterna & 0 & 0 & $x$ & 0 & 0 & 0 & 0 & 0 & 0 & 0 & 0 \\
\hline Slakdolf & Liparis liparis liparis & 1.7 & 0.9 & $x$ & 1.1 & 0.2 & 7.6 & 0 & 0.3 & 0.1 & 0 & 0.3 \\
\hline Smelt & Hyperoplus lanceolatus & 0 & 0 & $x$ & 0 & 0 & 0.4 & 0 & 0 & 0 & 0 & 0 \\
\hline Snoekbaars & Sander lucioperca & 1.2 & 0.3 & $x$ & 0 & 0.1 & 0 & 0.1 & 0.1 & 0 & 0.1 & 0 \\
\hline Snotolf & Cyclopterus lumpus & 0 & 0 & $x$ & 0 & 0 & 0 & 0 & 0 & 0 & 0 & 0 \\
\hline Spiering & Osmerus eperlanus & 10.9 & 108 & $x$ & 86.9 & 268 & 1260 & 804 & 888 & 121 & 101 & 88 \\
\hline Sprot & Sprattus sprattus & 0.2 & 0.3 & $x$ & 25 & 78.4 & 309 & 59.9 & 924 & 1191 & 1019 & 2445 \\
\hline Steenbolk & Trisopterus luscus & 4.7 & 0.5 & $x$ & 1 & 0.5 & 1.1 & 0.7 & 3 & 0.6 & 3.8 & 4.7 \\
\hline Stekelrog & Raja clavata & 0 & 0 & $x$ & 0 & 0 & 0 & 0 & 0 & 0 & 0 & 0 \\
\hline Tong & Solea solea & 4.2 & 7.7 & $\mathrm{x}$ & 2.7 & 0.4 & 0 & 0 & 0.2 & 0 & 0 & 2.5 \\
\hline Vierdradige meun & Enchelyopus cimbrius & 0 & 0 & $x$ & 0 & 0 & 0 & 0 & 0 & 0 & 0 & 0 \\
\hline Vijfdradige meun & Ciliata mustela & 0.3 & 0.3 & $\mathrm{x}$ & 0 & 0 & 0 & 0 & 0 & 0 & 0 & 0 \\
\hline Vorskwab & Raniceps raninus & 0 & 0 & $\mathrm{x}$ & 0 & 0 & 0 & 0 & 0 & 0 & 0 & 0 \\
\hline Wijting & Merlangius merlangus & 0.7 & 0.4 & $\mathrm{x}$ & 0.2 & 0.5 & 0.1 & 0.2 & 0.5 & 0 & 0.7 & 0.2 \\
\hline Zalm & Salmo salar & 0 & 0 & $\mathrm{x}$ & 0 & 0 & 0 & 0 & 0 & 0 & 0 & 0 \\
\hline Zandspieringen indet. & Ammodytes sp. & 49.8 & 0.1 & $x$ & 172 & 0 & 0 & 0 & 4.4 & 0 & 0 & 0 \\
\hline Zeebaars & Dicentrarchus labrax & 4.6 & 2.4 & $x$ & 0.5 & 0 & 0.1 & 0.3 & 1.1 & 0 & 1 & 8 \\
\hline Zeedonderpad & Myoxocephalus scorpius & 0.1 & 0.3 & $x$ & 0 & 0.1 & 0 & 0 & 0 & 0 & 0 & 0 \\
\hline Zeeforel & Salmo trutta trutta & 0.1 & 0.3 & $\mathrm{x}$ & 0 & 0.1 & 0.1 & 0.1 & 0 & 0 & 0 & 0 \\
\hline Zeenaalden indet. & Syngnathus sp. & 21.4 & 0 & $x$ & 0 & 0 & 0 & 0 & 0 & 0 & 0.5 & 0 \\
\hline Zeeprik & Petromyzon marinus & 0 & 0 & $x$ & 0 & 0 & 0 & 0 & 0 & 0 & 0 & 0 \\
\hline vislarven & larvo & 0 & 0 & $x$ & 429 & 0 & 0 & 0 & 16.1 & 3103 & 27783 & 38 \\
\hline
\end{tabular}




\section{Bijlage 2 Overige soorten 2018}

Totaal aantal gevangen in 2018

\begin{tabular}{|c|c|c|c|}
\hline Nederlandse naam & $\begin{array}{l}\text { Wetenschappelijke } \\
\text { naam }\end{array}$ & voorjaar & najaar \\
\hline Amerikaanse langlob-ribkwal & Mnemiopsis leidyi & & 340209 \\
\hline Zeedruif & Pleurobrachia pileus & & 30 \\
\hline E. maculata & Eucheilota maculata & & 6845 \\
\hline Kleine klokpoliep & Clytia hemisphaerica & & 359 \\
\hline Kruiskopkwalletje & Nemopsis bachei & & 4605 \\
\hline Parasolletje & Eutonina indicans & 27 & \\
\hline Haarkwal & Cyanea sp. & 14293 & \\
\hline Kompaskwal & Chrysaora hysoscella & & 7 \\
\hline Oorkwal & Aurelia aurita & 148 & 14 \\
\hline Zeepaddestoel & Rhizostoma pulmo & & 11 \\
\hline Brakwatersteurgarnaal & Palaemon varians & & 16 \\
\hline Chinese wolhandkrab & Eriocheir sinensis & 1 & \\
\hline Gewone garnaal & Crangon crangon & 56016 & 22 \\
\hline Gewone zwemkrab & Liocarcinus holsatus & 13 & 9 \\
\hline Gezaagde steurgarnaal & Palaemon serratus & 1015 & \\
\hline Hooiwagenkrab & Macropodia rostrata & & 1 \\
\hline P. longirostris & Palaemon longirostris & 3649 & \\
\hline Ringsprietgarnaal & Pandalus montagui & 32 & \\
\hline Strandkrab & Carcinus maenas & 6 & 18 \\
\hline Nonnetje & Limecola balthica & 118 & \\
\hline Dwerginktvissen indet. & Sepiola sp. & 188 & 1 \\
\hline Langvinpijlinktvissen indet. & Loligo sp. & & 1 \\
\hline Zeekat & Sepia officinalis & 1 & \\
\hline
\end{tabular}


Wageningen Marine Research

T: +31(0)317480900

E: marine-research@wur.nl www.wur.nl/marine-research

Visitors address

- Ankerpark 271781 AG Den Helder

- Korringaweg 7, 4401 NT Yerseke

- Haringkade 1, 1976 CP IJmuiden
Wageningen Marine Research is the Netherlands research institute established to provide the scientific support that is essential for developing policies and innovation in respect of the marine environment, fishery activities, aquaculture and the maritime sector.

Wageningen University \& Research is specialised in the domain of healthy food and living environment.

\section{The Wageningen Marine Research vision:}

'To explore the potential of marine nature to improve the quality of life.'

\section{The Wageningen Marine Research mission}

- To conduct research with the aim of acquiring knowledge and offering advice on the sustainable management and use of marine and coastal areas.

- Wageningen Marine Research is an independent, leading scientific research institute.

Wageningen Marine Research is part of the international knowledge organisation Wageningen UR (University \& Research centre). Within Wageningen UR, nine specialised research institutes of Stichting Wageningen Research (a Foundation) have joined forces with Wageningen University to help answer the most important questions in the domain of healthy food and living environment. 